\title{
Is There a g-factor of Genderedness? Using a Continuous Measure of Genderedness to Assess Sex Differences in Personality, Values, Cognitive Ability, School Grades, and Educational Track
}

\author{
Ville-Juhani Ilmarinen ${ }^{1 *}$ \\ Mari-Pauliina Vainikainen ${ }^{2,3}$ \\ Jan-Erik Lönnqvist ${ }^{1}$
}

${ }^{1}$ Swedish School of Social Science, University of Helsinki

${ }^{2}$ Centre for Educational Assessment, Faculty of Educational Sciences, University of Helsinki

${ }^{3}$ Faculty of Education, University of Tampere

* Corresponding author. Swedish School of Social Science, University of Helsinki, Finland.

Snellmaninkatu 12, PO Box 16, 00014 Helsinki, Finland. ville-juhani.ilmarinen@helsinki.fi.

$+358505560838$

This research was supported by the Academy of Finland research grant 338891 to V.-J. I. and by the Academy of Finland research grant 309537 to J.-E. L.

A preregistration for the study can be found at https://osf.io/6ksz9. The materials are permanently and openly accessible at https://osf.io/gpcyh/

This is the accepted version of an article published in European Journal of Personality.

\section{For citation use:}

Ilmarinen, V. J., Vainikainen, M. P., \& Lönnqvist, J. E. (2022). Is there a g-factor of genderedness? Using a continuous measure of genderedness to assess sex differences in personality, values, cognitive ability, school grades, and educational track. European Journal of Personality. https://doi.org/10.1177/08902070221088155 


\begin{abstract}
Some of the most persistently recurring research questions concern sex differences. Despite much progress, limited research has thus far been undertaken to investigate whether there is one general construct of genderedness that runs through various domains of human individuality. In order to determine whether being gender typical in one way goes together with being gender typical also in other ways, we investigated whether 16-year-old Finnish girls and boys $(N=4106)$ differ in their personality, values, cognitive abilities, academic achievement, and educational track. To do this, we updated the prediction-focused gender diagnosticity approach by methods of cross-validation for more accurate estimation. The preregistered analysis show that sex differences vary across domains $(D s=0.15-1.48)$, that fine-grained measures, such as grade profiles, can be accurate in predicting sex $(77.5 \%)$, whereas some summary indices, such as general cognitive ability, do not perform above-chance (52.4\%), and that the genderedness correlations, despite all being positive, are too weak (average partial correlation, $r^{\prime}=.09$, range .03-.34) to support a general factor of genderedness. Our more exploratory analyses show that more focus on gender typicality could offer important insights into the role of gender in shaping people's lives.
\end{abstract}

Sex differences; Femininity-masculinity; Cross-validation; Multivariate; Gender typicality 


\section{Introduction}

Some of the most persistently recurring research questions in the fields of personality and social psychology concern sex differences. There may be very few constructs within these fields that have not been investigated with respect to sex differences. Given both the research community's and the public's deep fascination with sex difference research, it can be considered surprising that very limited research has thus far been undertaken to investigate whether there is some type of g-factor of individual differences in genderedness. That is, does being gender typical in one way go together with being gender typical also in other ways?

We investigate whether 16-year-old girls and boys finishing Finnish elementary school differ in their personality traits, values, cognitive profiles and abilities, academic achievement, and educational track. Our first batch of results suggested that indeed they do, and we followed up by investigating whether gender typicality in one domain, such as personality, was associated with gender typicality in another domain, such as academic grades. If this were generally the case, one could argue that there is such thing as a prototypical boy or girl.

Sex, used here in its common-language meaning as referring to two binary categories, should not be conflated with gender, which consists of the meanings ascribed to male and female social categories within a culture. Research on sex differences has strongly focused on mean differences between two categories, whereas gender research has dispensed with measures of sex, replacing it with measures of gender identity and femininity-masculinity (Wood \& Eagly, 2015). Building on the work of Lippa and Connelly (1990) on gender diagnosticity, we constructed a dimensional variable reflecting to what extent the characteristics of the individual boy or girl are feminine vs. masculine. This variable bridges the distinct research traditions on sex and gender, and 
allows girls to receive high scores in masculinity, and vice versa. It should be ideally suited to investigate the extent to which individuals are gender typical.

We first introduce research on sex differences in personality, values, cognitive ability, academic achievement, and educational track. This research is explicitly on sex differences; that is, differences between two binary, natural, and fixed categories. We then introduce the concept of gender diagnosticity (Lippa \& Connelly, 1990), which we will employ to measure the genderedness of traits, values, etc. We will use the measure of gender diagnosticity to investigate the sex differences in the above domains, followed by examining whether being gender typical in one domain goes together with being gender typical in another domain.

\section{Sex Differences}

\section{Quantifying Sex Differences}

Sex difference research describes differences between females and males in characteristics. These can be differences in a certain characteristic such as trait agreeableness or they can be general (or “over-all”) differences in a set of characteristics belonging to a certain domain such as personality; e.g., differences in the five broad personality traits that constitute the Five-Factor Model (Costa \& McCrae, 1992). Sex differences on a single characteristic and differences in a set of characteristics are typically quantified with $d$ and $D$, respectively. The former is the standardized mean differences on a single dimension, whereas the latter is the distance between centroids in multivariate space (Del Giudice, in press).

The standardized metrics of $d$ and $D$ are comparable, but their interpretations are somewhat different. Whereas $d$ has direction (e.g., women are more agreeable than men, $d=0.2$ ), $D$ does not (e.g., the distance between sexes in personality is $D=1.0$ ). In the present study we will employ $D$, as we are not interested in a particular characteristic (e.g., agreeableness) or the direction of differences on that characteristic, but the overall magnitude of sex differences within certain 
domains (e.g., personality). $D$ should not be confused with averaging over multiple separately calculated $d$ values. $D$ indicates total distance, whereas $d$ is difference with a certain direction, and calculations of $D$, but not of average $d$, correct for the extent to which the variables that go into the computation of $D$ are correlated with each other. For these reasons, when asking how alike or different the sexes are, or making claims about the magnitudes of similarities and differences (e.g., men and women are more alike than different; Hyde, 2005), multivariate $D$ is preferable to $d$ (Del Giudice, 2009). It should also be noted that when, within a certain domain, one is operating at the broadest level of the hierarchy, at which all individual differences are coalesced into one variable,

one is not learning about $D$, but about the average univariate distance $d$. We next review research on sex differences within those domains that are included in the present research with emphasis on the evidence that best corresponds to the present study population, i.e. Finnish adolescents.

\section{Sex Differences in Personality}

The Five-Factor Model (FFM; Costa \& McCrae, 1992) is currently the most widely used framework for investigating individual differences in personality traits. Within this framework, personality traits are organized hierarchically, with narrow, specific traits, often referred to as facets, combining to define broad, global factors.

Computing $D$ based on the five broad factors identified by the FFM, sex differences ranging from $D=0.39$ to $D=1.02$ have been reported (across 22 countries; Mac Giolla \& Kajonius, 2019). Sex difference have been somewhat larger when $D$ has been computed based on thirty narrower personality facets, ranging from $D=0.87$ to $D=1.32$ (Mac Giolla \& Kajonius, 2019). Other measures to employ more narrow conceptualizations of traits have also yielded large differences (e.g., one study employing the 16PF personality measure, which measures 16 personality traits, reported a $D$ value of 2.71; Del Giudice et al., 2012). The largest sex differences have been observed in studies that have employed multigroup covariance and mean structure analysis (Del 
Giudice et al., 2012; Kaiser, 2019; Kaiser et al., 2019). Over-all sex differences, as assessed with $D$, have only been investigated in adult populations.

\section{Sex Differences in Personal Values}

We conceptualized personal values within the highly popular and influential framework provided by Schwartz's (1992) values theory. According to Schwartz (1992), personal values are transsituational goals that serve as guiding principles in the life of a person. They act as standards of what is most desirable when evaluating events, behaviors, and persons. Values differ from attitudes in that they transcend specific situations, are ordered in a person in a hierarchy of importance, set standards of desirability, and are less numerous and more central to personality than are attitudes.

Over-all sex differences in personal values have not been examined in either adult or youth populations. However, some large-scale studies have reported sex differences in single value priorities. Most of the basic values identified by Schwartz' values theory; that is, achievement, hedonism, stimulation, self-direction, universalism, benevolence, conformity, tradition, and security, show small sex differences. In one large-scale study, the median sex difference calculated across 70 countries and 127 samples was $d=.15$ (Schwartz \& Rubel, 2005). This does not, however, speak to over-all differences in values $(D)$. Although some of the sex differences in single values are similar across cultures, others are cross-culturally heterogeneous (Schwartz \& Rubel, 2005).

\section{Sex Differences in Cognitive Abilities}

Sex differences in cognitive performance have typically been measured either as univariate differences in some summary index (such as the intelligence quotient, IQ, or general cognitive ability, $g$ ) or differences in task performance in some specific tasks thought to tap into, for example, verbal or non-verbal reasoning and comprehension, perceptual and visuospatial ability, working memory, and processing speed (assessments more directly related to academic performance and 
achievement are covered in the next section). Although sex differences in cognitive test profiles, consisting of multiple different tasks, have sometimes been examined, no studies have calculated the over-all sex difference $D$ across profiles.

Sex differences in summary indices of cognitive ability tend to be very small or altogether absent (Colom et al., 2002). The literature in general does not support the existence of meaningful sex differences in general cognitive ability (Halpern, 2011). With regards to performance on more specific cognitive tasks, sex differences have been observed more consistently. Most often these have been from small to moderate in size, and there are many areas of cognitive ability for which meaningful sex differences have not been found (Halpern, 2011). Across several large-scale samples drawn from the US adolescent population between 1960 and 1992 (Hedges \& Nowell, 1995), girls performed better on reading comprehension (recalculated random effect meta-analytical estimate across the reported studies, $d=0.09)$, perceptual speed $(d=0.27)$, and associative memory $(d=0.26)$, whereas boys performed better on spatial ability $(d=0.19)$, mathematics $(d=0.16$; but $d$ $=0.07$ in an analysis run with similar but more recent data, Lindberg et al. 2012), and science $(d=$ 0.32). Cross-cultural meta-analyses on both spatial (Lauer et al., 2019) and mathematical (Lindberg et al., 2010) ability have corroborated the US results in the sense that boys have performed better, and further suggested that the sex differences tend to increase towards adolescence $(d \approx 0.50$ and $d$ $=0.23$, respectively). Furthermore, in a recent large-scale meta-analysis on working memory, adolescent girls performed better, especially on cued tasks $(d=0.24$; Voyer et al., 2021).

Importantly, within some areas (e.g., spatial or quantitative abilities), whether girls or boys perform better depends on the specific cognitive task (Halpern, 2011). This means that not only summary indices of general cognitive ability but also averaging across task within a more specific area of cognitive ability may mask sex differences (Johnson \& Bouchard, 2007). Another important finding has been that there is more variance among boys than girls in within-sex IQ-scores (Johnson et al., 2008; Strand et al., 2006). 


\section{Sex Differences in Academic Performance and Achievement}

The use of large-scale standardized international assessments designed to compare the quality of education across regions and countries has increased rapidly. The OECD's influential Program for International Student Assessment (PISA), a global survey of fifteen-year-olds' knowledge in core educational domains that includes measures in mathematics, reading, and science, is perhaps the most widely used international assessment. Small sex differences in the summary index have been reported across countries, with girls performing better in around $70 \%$ of countries, and boys performing better in only 4\% (Stoet \& Geary, 2015). Across countries included in PISA 2003, 2006, and 2009, differences in performance have varied between $d=-.42$ and $d=.20$ (negative $d$ indicates higher achievement among girls; Stoet \& Geary, 2015), with a mean $d=-.12$. In Finland, sex differences have been slightly larger than average (between $d=-.18$ and $d=-.28$; Stoet $\&$ Geary, 2015). Moreover, in PISA 2015, Finland was among the few countries in which girls outperformed boys on all measures (a small differences in science and mathematics and a medium difference in reading; Stoet \& Geary, 2018).

Girls also tend to perform better in terms of general academic achievement, as measured by grade-point average (Freudenthaler et al., 2008; Legewie \& DiPrete, 2012). This is also true in Finland (Pöysä \& Kupiainen, 2018). The picture becomes more nuanced if you look at grades in specific subjects; girls strongly outperform boys in some subjects (e.g., native language), but the differences are very small in others (e.g., math; Pöysä \& Kupiainen, 2018).

A recent study employed a similar prediction-focused method to ours to calculate multivariate $D$ based on the log odds of being a boy or girl. These predictions were based on three PISA academic skills and six academic attitudes (Stoet \& Geary, 2020). This multivariate set of variables produced large effect sizes across countries. Across the PISA waves of 2009, 2012, and 2015, country-specific $D$ s ranged from 0.84 to 1.26 , and universal $D$ s ranged from 0.75 to 1.13 . 
Thus, despite sex differences on any given academic achievement or attitude variable tending to be moderate at best, it seems that multivariate distances between boys and girls are notably larger.

\section{Sex Differences in Vocational Interest and Educational Attainment}

Some of the largest sex differences observed to date pertains to occupational preferences (Lippa, 1991, 1998, 2005), and a large-scale Internet-based survey suggests that this pattern (differences in People-Things dimension ranging from $d=0.96$ to $d=1.40$ ) holds across diverse cultural and ethnic boundaries (Lippa, 2010). A recent very large-scale study suggests that the underrepresentation of girls and women in science, technology, engineering, and mathematics (STEM) fields may even increase with increases in national gender equality (Stoet \& Geary, 2018). Indeed, the gender gap in Finland, which was ranked as the second most gender-equal of the 67 cultures or regions that were compared, was among the largest observed in that study.

More specific national level studies corroborate the above findings, indicating that girls and boys have clearly different preferences for secondary education. In general, girls are more likely to apply for high school as compared to vocational education (Pöysä \& Kupiainen, 2018). Regarding branches of education, some high schools are more popular among girls (e.g. arts and humanities), others among boys (e.g. mathematics and science; Pöysä \& Kupiainen, 2018). Sex differences are also very strong in preferences for vocational education; girls are much more likely to select certain vocations (e.g., health care) and boys to select other vocations (e.g. information technology; Pöysä \& Kupiainen, 2018).

\section{Prediction-focused Strategy for Sex Differences and Gender Diagnosticity}

In the present study, we prioritized a prediction-focused strategy (Yarkoni \& Westfall, 2017); i.e., we try to mimic the outputs of the true data-generating process when given the same inputs, without caring how that goal is achieved. This is in stark contrast to the explanation-focused strategy, which seeks to describe causal underpinnings and identify abstract principles. In terms of the distinction 
between the three key goals of personality science - description, prediction and explanation —our aim is to improve the accuracy and consistency of descriptive sex differences research by employing a predictive framework (for arguments and examples of how predictive models help descriptive research, see Mõttus et al., 2020). More specifically, we predict sex and investigate how these predictions fare as a function of which psychological and educational domains they are based on. Besides some general benefits of a prediction based approach, such as the avoidance of overfitting and the overestimation of effect sizes (Yarkoni \& Westfall, 2017), this approach allows for the straightforward integration of sex difference and gender research by means of statistics. A numeric value predicting the sex of the individual is calculated for each individual separately, and the distributions of these values (means, variance parameters) can be employed to estimate multivariate sex differences, analogous to Mahalanobis’ $D$ (see also Lönnqvist \& Ilmarinen, 2021; Stoet \& Geary, 2020). The goal of predictive personality research is often to maximize the prediction of life outcomes (Mõttus et al., 2020), but this is not our goal. Rather our goal is to investigate the signal to noise ratio of different predictors in the prediction of sex (in out-of-sample datasets). This benefits the descriptive goals of sex differences research, e.g., by shedding light on the general architecture of individual differences in relation to sex, and by signaling the limits of descriptive (or explanatory) models (Mõttus et al., 2020).

\section{Gender Diagnostic Predictions of Sex in Multivariate Sex Difference Estimation}

The gender diagnosticity approach (Lippa \& Connelly, 1990) is based on the rationale that within-sex gender differences in psychological constructs are defined by between sex differences in these constructs (Terman \& Miles, 1936). Gender diagnosticity uses Bayesian posterior probabilities to indicate how female-like or male-like an individual is given observed differences between sexes in a population (Lippa \& Connelly, 1990). These probabilities can be derived by statistical approaches such as linear discriminant analysis (Lippa \& Connelly, 1990) or logistic 
regression (Pelletier et al., 2015), in which a linear combination in a set of attributes is weighted to maximally differentiate between females and males.

The methods employed in gender diagnosticity research produce predictions of sex - the probability of being female or male given a set of attributes; nevertheless, the rationale is not to classify people, but to obtain a continuous measure of gender (Lippa \& Connelly, 1990). This measure indicates the gender typicality of the individual with regards to the given set of attributes (Young \& Sweeting, 2004). This typicality is given on a probability scale ranging from 0 to 1 , interpreted as indicating the extent to which an individual's attributes match with the attributes that are higher or lower among one sex (Young \& Sweetling, 2004). This method thus allows for a girl to be "boyish" and a boy to be "girlish". Studies employing gender diagnosticity have, for instance, shown that behavioral and attitudinal boyishness predict substance use among both boys and girls (Mahalik et al., 2015).

Research building on the concept of gender diagnosticity typically employs discriminant analysis or logistic regression to see the predictive power of a certain set of variables in assigning a Bayesian probability that a participant is male or female (e.g., Lippa, 1991; Lippa and Connelly 1990). However, the common method for estimating over-all sex differences is Mahalanobis' $D$ (Del Giudice, 2009; Mahalanobis, 1936). Fortunately, gender diagnostic sex predictions based on discriminant analysis and logistic regression share many of the characteristics of Mahalanobis' $D$; both methods are based on obtaining linear combinations that maximize sex differences and both take into account covariation between multiple dimensions, allowing for the examination of sex differences on a single variable whilst holding others constant. They also produce comparable metrics; i.e., because both discriminant analysis and logistic regression with multiple input variables estimate coefficient weights that maximize the distance between two group centroids, the standardized metrics; that is, distance between the centroids and predicted group affiliation, closely corresponds to the standardized multivariate distance given by Mahalanobis' $D$ (the unstandardized 
metrics, however, would not be equal; e.g., logistic regression produces logistically distributed predicted values that are transformed into probabilities). This means that the axis between centroids in multivariate space can be used not only to index femininity-masculinity (Del Giudice, in press), but to also estimate sex differences (Lönnqvist \& Ilmarinen, 2021; Stoet \& Geary, 2020).

In the present research we estimated $D$ with logistic regression instead of with Mahalanobis' $D$ or discriminant analysis. The benefits of logistic regression over discriminant analysis are that the data does not need to be multivariate normal and that logistic regression can make use of a wide variety of variables, including binary and multi-category nominal variables (Pohar et al., 2004; Press \& Wilson, 1978). Moreover, logistic regressions allow for cross-validation methods that control for overfitting (Mahalanobis' $D$ capitalizes on chance, but see also Del Giudice, in press, for a version of Mahalanobis' $D$ that seeks to avoid this). Most importantly, logistic regression allows for the study of multivariate sex differences employing gender diagnostic distributions of femininity-masculinity, whereas Mahalanobis' $D$ puts the focus on one single number that indicates the distance between the sexes.

In the Supplementary Online Materials (SOM), we provide a comparison of logistic regression, linear discriminant analysis, and Mahalanobis' $D$ in the estimation of $D$ in three different simulated data scenarios. Logistic regression accurately estimated sex differences in all scenarios. That the performance of logistic regression was similar to that of Mahalanobis' $D$ and discriminant analysis suggests that it can be used also with data that satisfies the rather stringent assumptions of the latter, besides being the obvious choice when these assumptions are not satisfied (e.g., non-normal or categorical data). In addition, there are clear benefits of obtaining predictions at the level of individual, as these allow for the investigation of the (co)variances of sex predictions across multiple domains. Finally, the simulations show that the regularized version of logistic regression should be preferred, as it performed similarly to other estimates in a scenario in which an actual effect was present, but outperformed them in the absence of an effect. 


\section{Constructing Gender Diagnostic Femininity-Masculinity Measures}

Being prediction-focused, the gender diagnosticity approach to measuring gender identity differs from more traditional approaches in that it does not a priori define which attributes are typical of each sex but seeks for weighted linear combinations that maximally differentiate between the sexes (for a review, see Wood \& Eagly, 2015). This agnostic standpoint as to what attributes are typical of which gender should guard against the influence of gender stereotypes (Lippa \& Connelly, 1990). Although gender diagnosticity is based on predictive modeling, it has been predominantly used from a personality assessment perspective (e.g., as a tool with which to measure masculinity-femininity). From this perspective, gender diagnosticity measurement, with sex as the criterion, belongs to the family of empirical criterion-keyed approaches to personality measurement (Ozer \& Reise, 1994). The quality of criterion-keyed measurement is strongly dependent on the sampling of the attributes that are used to construct the linear combinations that predict the outcome (Ozer \& Reise, 1994). This means that the most extensive set of variables should always be used, especially as novel regression methods allow for further variable selection that prevents overfitting. The use of an extensive non-aggregated set of variables is not only ideal for the predictive approach in general (Mõttus et al., 2020), but also eliminates the risk of narrow but meaningful associations being neglected due to variable aggregation (Del Giudice et al., 2012; Johnson \& Bouchard, 2007).

The gender diagnosticity approach allows for the construction of a continuous gender measure based on any variable set. It has been used in the domains of personality (Lippa \& Hershberger, 1999; Loehlin et al., 2005), behaviors (Mahalik et al., 2015), political attitudes (Lönnqvist \& Ilmarinen, 2021), occupational preferences (Lippa, 1998), and leisure activities (Leversen et al., 2012; Young \& Sweeting, 2004). In terms of psychological characteristics, however, there are very few studies on the associations between estimates of gender typicality derived from different psychological domains. 
Associations between gender-related attributes across different sub domains of vocational interests have been investigated in two studies (Ashton \& Lee, 2008; Lippa, 2005), and two other studies have mapped gender across a more diverse set of areas of individual variation (Pozzebon et al., 2015; Twenge, 1999). However, none of these studies can be considered a rigorous and powerful tests for a general factor of genderedness. Three major reasons for this are that (1) the most studied individual differences in personality traits, intellectual abilities, and academic performance have not been included in these studies; (2) the agnosticism of predictive modelling has not been put to use, with variables selected on ad hoc inconsistent and arbitrary bases, leaving the results to be potentially skewed by gender stereotypes; and (3) the samples in these studies have been small and non-representative. To help illustrate the advantages of predictive modelling, we present in more detail a previous study that employed methods similar to the few other studies that have investigated gender typicality employing estimates from different domains. Twenge (1999) had two hundred college freshmen rate (on a scale from 1 to 5) a set of 131 occupational preferences, and selected those 60 that showed a statistically significant $(p<.05)$ sex difference. The responses to these 60 items were then summed without weighting the items or considering the correlations between the preferences. This is in stark contrast to our employment of logistic regression, which accounts for the overlap between variables and employs cross-validation to weight the contributions of each variable in terms of its unique predictive performance in the prediction of sex in an independent sample.

Early studies on gender diagnosticity used the same data set for both constructing and testing the linear models (Lippa, 1998; Lippa \& Connelly, 1990). This approach bears the risk of overfitting, which increases performance within that specific data set, but decreases it in similar data sets drawn from the same population (Yarkoni \& Westfall, 2017). In the present context, overfitting would, by inflating associations, be expected to overestimate both sex differences and the associations between gender diagnostic femininity-masculinity scores based on different 
domains. That is, overfitting would be expected to distort results pertaining to some of the most central questions of gender diagnosticity research. Predictive cross-validation methods — recently introduced also into other areas, such as personality research (Mõttus \& Rozgonjuk, 2019; Seeboth \& Mõttus, 2018) — need therefore to be employed in gender diagnostic measures.

Going from a set of variables predicting sex in a logistic regression to indexing the estimates of interest, cross-validation is used at two stages. The data are initially split into two parts: training and testing data. The first cross-validation is a k-fold cross-validation that is used to obtain coefficient weights that minimize prediction error between $k$ number of separate folds of data drawn from the training data (Yarkoni \& Westfall, 2017). These k-fold methods, often implemented in penalized or regularized regression analyses (McNeish, 2015), allow for a large number of variables as predictors, which is an ideal feature in a strategy that is focused on prediction rather than explanation (Yarkoni \& Westfall, 2017) and in scenarios in which there are tens, hundreds, or more plausible predictors. The penalization procedure, in simplified terms, shrinks all the irrelevant predictors to zero, or very close to zero, depending on the specific regression analysis variant, thereby minimizing their influence on the predictions (McNeish, 2015). No a priori decisions regarding the included variables are necessary. The second cross-validation occurs when the optimized coefficient weights are used for predicting sex and investigating the associations of different predictions of sex in the testing data. The results of this cross-validation can then be indexed in the form of standardized mean differences between groups of men and women (analogous to multivariate $D$ or univariate $d$ ) or as correlations between different measures of gender. This two-phase cross-validation approach improves the accuracy of estimates, whilst allowing for comparison to other studies on sex differences. It also retains individual-level predictions that can be used to investigate bivariate associations and look at other distributional parameters, such as variances within each sex, allowing, for instance, for investigating whether the distributions of femininity-masculinity among men and women are mirror-images of each other. 
Multivariate sex difference estimation and follow-up procedures for examining gender diagnostic distributions, as employed in the present study, are available in the multid -package for the $\mathrm{R}$ environment (Ilmarinen, 2021).

\section{The Present Research}

The present study, conducted with a large representative sample of adolescents at the end of their lower secondary education, employs a predictive modeling approach to the measurement of sex differences and individual gender typicality in the domains of personality, personal values, cognitive abilities, academic achievement, and vocational interests (referred to as optional subjects and applications for secondary education in the below preregistered research questions). Our first purpose was to examine the magnitude of sex differences in each domain. Second, we examined the possible differences between narrower measures (e.g., personality facets, cognitive tests, and individual grades) that contain a more fine-grained operationalization of the domain and possibly additional and important information over the more commonly used broad bandwidth measures and summary indices (e.g., personality factors, general factor of cognitive ability, or grade-point average) in predictions of sex and sex differences. Our approach is agnostic is the sense that it does not commit us to any particular perspective in debates on how structural models of psychological constructs should be understood. Rather, we posit that the proper level of aggregation in psychological and educational sex difference research is the level at which the prediction of sex and the distance between the sexes is maximized. Our third purpose was to examine whether there is something like an underlying cross-domain "g-factor" of genderedness; that is, are individuals (boys or girls) who, in terms of gender, are more "boyish" in one domain, such as personality, also more "boyish" in another domain, such as academic achievement. The preregistered research questions are:

1. Are there sex differences in the following domains: 

a. Personality
b. Personal values
c. Cognitive test performance
d. Academic achievement
e. Optional subjects

f. Applications for secondary education

2. Are more fine-grained operationalizations of personality, cognitive performance, academic achievement, and applications for secondary education more informative regarding sex differences and gender?

3. Are continuous gender measures domain specific or generalizable across psychological and academic domains?

We also made a preregistered prediction regarding research question 2. Based on previous results suggesting that narrower characteristics will outperform broader characteristics in the prediction of various outcomes (Mõttus et al., 2017, 2019; Paunonen \& Ashton, 2001), we expected the fine-grained operationalizations to also do better also in terms of being better predictors of sex.

\section{Method}

\section{Preregistration}

The hypotheses and the analysis plan of this study were preregistered beforehand (see Nosek et al., 2018 , for the benefits of preregistration). The preregistration can be found at https://osf.io/6ksz9?view_only=f8f4592e8c7f4af08ce1befde9a75f33. The preregistered analysis plan included decisions regarding data preparation, variable transformations, data-analytical choices, and statistical inference. All decisions were preregistered before any analyses were run. 
Only missing values and descriptive statistics were examined prior to the preregistration; this was done to determine which variables could be included and how to best treat missing values. The results of all preliminary examinations are presented in the preregistration. Below, the method, such as it was described in the preregistration, is presented. Any additions and deviations from the preregistered plan are highlighted (in addition to the highlighted changes, please note that research questions 2 and 3 are research question 5 and 2 in the preregistration, and research questions 3 and 4 in the preregistration will be covered in a separate paper).

\section{Open data statement}

In agreement with the Education Department of the city where the study was conducted, the data are stored on a private university network to which researchers can gain access only by application and no part of the data are allowed to be downloaded from that network to another location. Doing so would be a breach of contract. Thus, the data are not available.

\section{Participants and Procedure}

Participants were 4106 adolescents (49.5\% male) in their last year of Finnish comprehensive school and lower secondary education (ninth grade). The mean age of the participants was $15.79(S D=$ 0.41). Participants were from 242 classrooms from 49 urban schools in Southern Finland.

The study was conducted in cooperation with the Education Department of the region in which the study was conducted (for more details, see Lönnqvist et al., 2011). Their lawyers were involved in drafting the agreement that specified the research plan and saw to it that the research met all ethical protocols and standards. The participants completed a battery of cognitive tests and questionnaires. The measures were completed in a double lesson (90 minutes), after which regular schoolwork continued. Academic achievement (grades) and preferences for secondary education were obtained from archival data. As stated in the preregistration, in case of overly consistent 
patterns; that is, eight or more of the same answers in a row in the self-report personality or value questionnaires, data in these domains was coded as not available.

\section{Measures}

Personality. Personality was measured by having participants $(n=2565)$ complete, in self-report format, the National Character Survey (NCS; Terracciano et al., 2005; for the approved Finnish translation, see Realo et al., 2009). This measure - designed to mimic the original 240 item NEO PI-R (Costa \& McCrae, 1992) - consists of 30 bipolar items, of which each measures a facet of the FFM (Costa \& McCrae, 1992). Cross-instrument correlations between the NCS personality factors and longer measures of the FFM personality factors tend to vary between .70 and .80 (Konstabel et al., 2012). Participants were instructed to rate themselves on a seven-point scale using the 30 NCS items and at the top of the questionnaire was printed 'I am...'. For instance, the two poles of the Extraversion Warmth facet were 'Friendly, warm, affectionate' and 'Cool, aloof'. Reliabilities, indexed by $\omega_{\mathrm{h}} / \alpha / \omega_{\mathrm{t}}$ (see Revelle $\&$ Condon, 2019) were $.65 / .78 / .83, .63 / .74 / .80, .47 / .55 / .66$, $.63 / .69 / .75$, and $.63 / .75 / .80$ for Neuroticism, Extraversion, Openness to Experience, Agreeableness, and Conscientiousness, respectively.

Values. Personal values were measured with the ten-item Short Schwartz' Value Survey (SSVS: Lindeman \& Verkasalo, 2005). Participants $(n=2637)$ were presented with the name of each of ten basic values (Power, Achievement, Hedonism, Stimulation, Self-Direction, Universalism, Benevolence, Tradition, Conformity, and Security) identified by Schwartz's values theory (Schwartz, 1992) along with the related original value items from the longer original Schwartz' Value Survey (Schwartz, 1992, 1996). For instance, participants were asked to rate on a 9-point scale from 0 (opposed to my principles), 1 (not important), 4 (important), to 8 (of supreme importance), the importance of "Power, that is, social power, authority, wealth" and "Achievement, that is, success, capability, ambition, and influence on people and events" as life-guiding principles. 
A similar phrasing was used for all 10 values. Correlations between basic values as measures by the SSVS and by longer measures of values tend to range from .45 to .70 .

Cognitive ability. There were nine tests of cognitive performance. Altogether 3621 participants completed at least one test, and $2628(72.6 \%)$ completed all tests. In terms of the general taxonomy of cognitive abilities (Schneider \& McGrew, 2012), our tests assessed domains and sub-domains of fluid reasoning, reading and writing, short-term memory, and quantitative knowledge. General cognitive ability was operationalized as the factor score of the first factor obtained in principal axis factor analysis of all test scores. Reliability indices for general cognitive ability were $\omega_{\mathrm{h}}=.73, \alpha=$ .81 , and $\omega_{\mathrm{t}}=.83$. The correlation matrix between cognitive tests is shown in Table $\mathrm{S} 1$.

Invented mathematical concepts. In a modified version of the Creative-Quantitative test in Sternberg's Triarchic Abilities Test (Sternberg et al., 2001), students $(n=3424)$ were presented with the novel concepts "lag" and "sev," the definitions of which varied in a way that was conditioned on the involved numbers (whether the first number is greater than, equal to, or less than the second number). Participants answered to ten items (e.g., "How much is 2 sev 3 lag 4?”), each of which had four multiple-choice alternatives. The sum score on the test (one point for each correct item) was used $(M=5.88, S D=2.59)$. Scale reliability, indexed as item-response theory based reliability for dichotomous data (Cheng et al., 2012) was $\pi_{(2)}=.79$, whereas alpha for nominal scales (Cohen, 1960) was $\alpha=.76$.

Hidden arithmetic operators. In a task based on the quantitative-relational arithmetic operators task (Demetriou et al., 1996), ten items (e.g. "6 a 2 =3, what is a?”) with multiple choice $(+,-, \times$, and $\div)$ were given. One point was given for each correct answer and the sum of correct answers was used $\left(n=3135, M=3.66, S D=2.04, \alpha=.75, \pi_{(2)}=.80\right)$.

Visual working memory. This ten-item task measured the capacity of the visuospatial sketchpad (Logie \& Pearson, 1997; Wilson et al., 1987). Participants were presented with ten grids of different 
size where some of the squares were painted black. After showing the grid for three seconds, participants were asked to reproduce the grid by coloring the correct squares in an empty grid. One point was given for each correctly reproduced grid and the sum of correct answers was used as score of visual working memory $\left(n=3621, M=5.55, S D=2.42, \alpha=.74, \pi_{(2)}=.76\right)$.

Mental arithmetics. Participants listened to the teacher read aloud a mathematics problem (e.g. "Employee earned 360 euro and was paid 40 euro per day. How many days did the employee work?") and responded on their answering sheet. The task comprised of eight items adapted from the Mental Arithmetics task of the Wechsler Adult Intelligence Scale-Revised (Wechsler, 1981). One point was given for each correct answer and the sum of correct answers was used as score of mental arithmetics $\left(n=3621, M=4.73, S D=2.47, \alpha=.82, \pi_{(2)}=.83\right)$.

Analogical reasoning. In each of eight tasks adapted from the geometric analogies test (Hosenfeld et al., 1997), participants were presented with an initial pair of geometric figures that were transformations of each other. Simultaneously, participants were to find a match for a third figure (from five options) using the same transformation as in the initial pair. One point was given for each correct answer, and the sum of correct answers was used as a score for analogical reasoning ( $n=$ $\left.2906, M=3.74, S D=2.28, \alpha=.73, \pi_{(2)}=.75\right)$.

Reading comprehension: Multiple-choice. A narrative passage concerning a visit to a travel agency was followed by four multiple choice questions (four options, one of which was correct; Lehto et al., 2001). Participants were allowed to consult the passage when answering. One point was given for each correct answer, and the sum of correct answers was used as a measure of multiple-choice reading comprehension $\left(n=3262, M=2.75, S D=1.25, \alpha=.63, \pi_{(2)}=.65\right)$.

Reading comprehension: Macroprocessing. To test for multi-layer mental text representation and macroprosessing (i.e., distinguishing central themes from minor details; Lyytinen \& Lehto, 1998), participants first read a passage about US cities in $19^{\text {th }}$ century (279 words and six paragraphs). 
After this, participants selected the two most important topic statements and six main themes out of 16 statements (the eight remaining were considered minor details). To give some examples, a topic statement was "The passage tells about the development of cities in the USA in the 1800s", a main points was "Slums were problematic neighbourhoods", and a minor detail was "Garbage had been eaten by pigs in the street". The student had access to the text when responding. One point was given for each correctly identified statement, and the sum of correct answers was used as a measure of text macroprocessing $\left(n=2871, M=7.54, S D=3.32, \alpha=.70, \pi_{(2)}=.69\right)$.

Verbal proportional reasoning. The missing premises task was adapted from the Ross test of Higher Cognitive Processes (Ross \& Ross, 1979). The task consisted of eight items each presenting participants with one premise and the conclusion. Participants then selected a second premise, based on which the conclusion would be correct, from five alternatives. Only one of the alternatives was correct, and one point was given for each correct answer. The sum of correct answers was used as a measure of verbal proportional reasoning $\left(n=3522, M=4.38, S D=1.98, \alpha=.65, \pi_{(2)}=.67\right)$.

Scientific reasoning. A Piagetian formal operations tasks was used to assess level of formal thinking (Hautamäki, 1989; Thuneberg et al., 2015). For instance, participants were asked to consider F1 drivers, cars, tires, and racetracks (four variables each, all with two given values from which to select: Räikkönen, Schumacher; Ferrari, McLaren; Michelin, Bridgestone; Monaco, Silverstone). In half of the items, subjects were given a set of values for the four variables (such as Räikkönen, Ferrari, Michelin, Monaco) and asked to construct another set that would clarify the role of a specified variable (say, tires). Subjects should produce a set of values for all four variables in such a way that would allow for the focal variable to be studied in an unconfounded pair (see Strand-Cary \& Klahr, 2008). In the other half of the items, the subjects are given a dual set (Räikkönen, McLaren, Michelin, Monaco vs. Räikkönen, Ferrari, Michelin, Monaco) and asked if this is a good test of, for example, the role of tires (in this case, the question is confounded for tires, unconfounded for the nonfocal variable car). The response options were "yes", "I do not know", 
and "no", with "I do not know" always coded 0 . The number of items was six, and one point was given for each correct answer. The sum of correct answers was used as a measure of scientific reasoning $\left(n=3413, M=2.51, S D=1.63, \alpha=.67, \pi_{(2)}=.77\right)$.

Academic achievement. Academic achievement was ope ${ }^{\mathrm{r}}$ ationalized as grades (archival data) received in 16 school subjects at the end of the school year ( $9^{\text {th }}$ grade): native language, first foreign language, biology, physics, geography, history, chemistry, home economics, handicraft, ethical studies, visual arts, physical training, mathematics, music, health education, and social studies. We included only school subjects and courses that were obligatory. Pupils are graded on a scale from 4 to 10. Under some very exceptional circumstances, pupils can receive the grade $\mathrm{S}$ (accepted). These were coded as unavailable. The first foreign language (A1) was most often English (91.5\%). Other A1 languages were German (1.9\%), Spanish (0.3\%), French (3.0\%), Russian (0.6\%), and Swedish (2.7\%). The total number of participants for whom all obligatory grades were available was 3991 . Grade-point average (GPA) was calculated from the arithmetic mean across school subjects $(M=$ $8.18, S D=0.96)$.

Selection of optional school subject. Optional school subjects were obtained from archival record and dummy-coded. Optional languages were left out because each student's native language dictates which languages are mandatory and which are optional for that student. Students could have more than one optional subject. Of the total 3773 participants with at least one optional subject, 891 (23.6\%), 1750 (46.4\%), $996(26.4 \%)$, and $136(3.6 \%)$ had one, two, three, or more than three optional subjects, respectively. The most common optional school subjects were home economics $(n=2630)$, handicraft $(n=1557)$, visual arts $(n=1136)$, physical training $(n=1600)$, music $(n=782)$, and mathematics $(n=101)$. Other subjects were selected by less than 40 participants. Not every school offered each subject as an option. Only subjects chosen by at least 10 participants were included; besides those presented above, these were biology, history, chemistry, and social studies. 
Secondary education. Preferences for secondary education were obtained from the official application forms $(n=4056)$. Students could apply for up to five secondary educations, but we considered only their number-one choice. Two different variables were constructed based on this information:

Preference for academic/vocational track. One variable indicated whether the participant preferred an academic track ("lukio" in Finnish, sometimes translated as (senior) high school, upper secondary school, college, or gymnasium, we will use high school; $n=2959$ ) or vocational track (institutes that offer vocational education and training; $n=1097$ ).

Preference for field of education. A second variable indicated the student's most preferred field of education. We mostly followed the categorization provided on the website that is informed by Finnish National Agency for Education and Ministry of Education and Culture (studyinfo.fi), but collapsed some schools or fields with low numbers of applicants. Vocational institutes were classified as Cultural (e.g. artisan or media-assistant; $n=70,1.7 \% / 6.4 \%$ of all/vocational applications), Health Care (e.g. practical nurse; $n=134,3.3 \% / 12.2 \%$ of all/vocational applications), Beauty Care (e.g. hairdresser or make-up artist; $n=68,1.7 \% / 6.2 \%$ of all/vocational applications), Educational (e.g. youth worker, family worker, or physical-education instructor; $n=17,0.4 \% / 1.5 \%$ of all/vocational applications), Natural Resources and Environment (e.g. forest worker, animal attendant, or agriculture; $n=20,0.5 \% / 1.8 \%$ of all/vocational applications), Security (e.g. security guard; $n=30,0.7 \% / 2.7 \%$ of all/vocational applications), Business (e.g. graduate of a commercial institute [merkonomi in Finnish]; $n=215,5.3 \% / 19.6 \%$ of all/vocational applications), Information Technology (e.g. vocational qualification in business information technology [datanomi in Finnish]; $n=111,2.7 \% / 10.1 \%$ of all/vocational applications), Technology and Traffic (e.g. machinist, electrician, process worker, or builder; $n=332,8.2 \% / 30.3 \%$ of all/vocational applications), and Travel, Catering, and Domestic Economics (e.g. baker, hotel clerk, tour guide; $n=100,2.5 \% / 9.1 \%$ for all/vocational applications). 
High schools were classified as Language emphasis $(n=318,7.8 \% / 10.7 \%$ of all/high school applications), Cultural emphasis ( $n=379,9.3 \% / 12.8 \%$ of all/high school applications), Sports and Exercise emphasis ( $n=280,6.7 \% / 9.1 \%$ of all/high school applications), Natural Science emphasis ( $n=94,2.3 \% / 3.2 \%$ of all/high school applications), Social Science emphasis $(n=70,1.7 \% / 2.4 \%$ of all/high school applications), Business emphasis $(n=31,0.7 \% / 1.0 \%$ of all/high school applications), and Steiner High Schools ( $n=25,0.6 \% / 0.8 \%$ of all/high school applications). The majority of first-choice high school applications were for high school without any specific emphasis (General High Schools; $n=1766,43.5 \% / 59.7 \%$ of all/high school applications). Because there were only few first-choice applications to equestrian $(n=1)$, aviation $(n=4)$, and Christian $(n=1)$ high schools, these were included in the General High Schools - category (after this inclusion, $n=1772$, $43.7 \% / 59.9 \%$ of all/high school applications).

Between-classroom variation in continuous variables. Classroom membership did not, as expected, explain much variance in personality and values. Intraclass correlations (ICC) equal to or larger than .05 were only observed for Openness to Experience item 'Unartistic, uninterested in art Sensitive to art and beauty' $(\mathrm{ICC}=.05)$ and Universalism values $(\mathrm{ICC}=.05)$. For cognitive tests and grades, substantial variation between classrooms was observed for all variables as well as for general cognitive ability and GPA (ICCs for these variables ranged between .11 and .33). As preregistered, we did not transform variables for which ICCs (intra-class correlations) were smaller than .05 , but when ICC was larger than .05 , scores on this variable were centered around the classroom mean. Centering was done around the grand mean in classrooms for which we had less than seven data points available.

\section{Statistical Analysis}

The statistical analysis was conducted within the predictive modeling framework (Yarkoni \& Westfall, 2017). Femininity-Masculinity (FM) scores for each individual and each domain were constructed using logistic regression with elastic net penalty (McNeish, 2015). The log-odds 
coefficients obtained from predicting sex in one sample (training sample) were used to calculate the scores in a different, independent, sample (testing sample). The predicted values constituted our measure of FM. Separate analyses were run for each domain and at different bandwidths, giving us distinct coefficients and distinct FM scores for personality (domains and facets), personal values, academic achievement (GPA and grade profiles), cognitive ability ( $g$ and test profiles), optional subjects, and application for secondary education (high school vs. vocational institute and different educational fields).

For the investigation of sex differences (research question 1), we computed the standardized mean difference between girls and boys in FM scores (separate analyses for each domain and at different bandwidth; for a similar approach, see Stoet \& Geary, 2020). To examine the possible benefits of more nuanced measurement in predicting sex (research question 2), we looked at whether the narrower measures could statistically significantly add to the predictive power of models including the broader measures. To investigate a possibly underlying g-factor of genderedness (research question 3), we looked at the Pearson's correlation coefficients between FM scores in different domains and examined partial correlations between these FM-variables in the network format to understand their domain-specificity and generality. However, after preregistration, we realized that both the zero-order correlations and partial correlations that we planned on presenting would be confounded by sex differences. To address this third variable problem, the presence (or absence) of a "g-factor" was examined from correlations from which sex was partialed out, from within-sex correlations (for similar reasoning, see Ashton \& Lee, 2008; Twenge, 1999; and also see Figure S1 in the SOM that illustrates how sex differences may confound zero-order associations and fail to distinguish between-sex sources of variance from within-sex sources of variance), and from the association networks of these correlations. This allowed us to estimate the extent to which FM-scores have unique associations, as compared to resulting from common variance. Regarding terminology, "partial correlation" will be used to refer 
to sex-partialized association and "unique partial correlation" to sex- and other FM-score partialized associations. We also ran additional non-preregistered exploratory tests for a common factor. In these, different variants of factor analysis were run on the sex-partialized correlation matrix. In general, we report all results from the non-preregistered analyses under the "exploratory" subheadings. However, we make an exception for research question 3, which we consider confirmatory despite the preregistered method of analysis being too poorly specified.

Statistical inferences were based on $95 \%$ percentile confidence intervals that were obtained by repeating one thousand times the procedure that included i) imputing missing values for personality, personal values, cognitive tests, and grades [mention of grades was mistakenly omitted from the preregistration description of this working phase] ii) splitting the data into training and testing sets iii) obtaining log-odds FM coefficients from the training set via penalized logistic regression iv) calculating FM scores in the independent testing data set for each individual v) calculation of the test statistic of interest (mean difference, correlation, difference between mean differences). When the resulting confidence interval did not include zero, the test was interpreted as statistically significant.

Penalized logistic regression analyses were run with the glmnet package (Friedman et al., 2010) in R (R Core Team, 2019). Penalized regression is especially suitable when there are many highly intercorrelated potential predictor variables - the method offers parsimonious and precise models, which leads to better predictive performance in independent datasets. In the penalized regression (training data), sex was regressed on each of the above-described domain- and bandwidth specific variable sets by binomial link regression in which the regularization parameter was obtained using 10-fold cross-validation that sought to minimize cross-validated prediction error (recall that cross-validation was used at two stages, first within the training data for elastic net regression and subsequently when the original data was split into training and testing sets). Missing data was imputed with the mice package (van Buuren \& Groothuis-Oudshoorn, 2011). Imputation 
was done separately in each training-testing permutation - variability in the data imputation was thus reflected in the uncertainty of the estimates. All the analysis scripts with related output are available at https://osf.io/gpcyh/. See also the multid package in R (Ilmarinen, 2021) for a streamlined estimation of multivariate sex differences and for examining FM score distributions with the above-described procedure.

\section{Statistical Power}

Statistical inference in the present study were based on the distributions of estimates across trainingtesting permutations. However, for simplified estimates, based on two-way $t$-tests run on a dataset the size of a single testing dataset (half of the total sample size in each domain, equal number of boys and girls assumed), we computed the smallest detectable effects with .80 statistical power and type-I error set at .05 , the sample sizes were sufficient to detect sex differences between sizes $d=$ 0.12 and $d=0.16$. Regarding the bivariate correlations between FM scores, the sample sizes (ranging between $n=1144$ and $n=2041$ in the testing data) were sufficient for detecting effects between sizes $r=.06$ and $r=.08$.

\section{Results}

\section{Variable Selection in Penalized Logistic Regression in the Training Data set}

Results from the variable selection procedure are presented in detail in the SOM. One domain at a time, we ran penalized logistic regressions in training data to obtain log-odds coefficient weights for each variable. The distributions of these weights and the number of permutations with a non-zero coefficient are presented in SOM Tables S2-S12. These tables show how strongly each variable within each domain was associated with sex. Below we summarize the results for each domain. In addition, descriptive statistics and univariate sex differences for each continuous variable can be found in SOM Table S13. The descriptive statistics for optionally selected subjects and preferences for secondary education can be found in SOM Tables S14 and S15, respectively. 
Each of the five broad personality factors was selected in every permutation (Table S2). All coefficients were negative, indicating that higher scores on Neuroticism, Extraversion, Openness to Experience, Agreeableness, and Conscientiousness were all associated with being a girl. Regarding personality facets, there was more heterogeneity across permutations (Table S3). Six facets (N1, $\mathrm{O} 2, \mathrm{~N} 3, \mathrm{O} 3, \mathrm{C} 3, \mathrm{E} 6$, and $\mathrm{O} 6)$ were retained in every permutation.

Of the ten personal basic values (Table S4), across all permutations, power and tradition were non-zero and higher among boys, whereas universalism and benevolence were, in similar fashion, consistently higher among girls.

General cognitive ability (Table S5) was selected in almost all permutations (it was non-zero in 997 permutations). It was always negative, indicating that girls had higher scores. Using the entire battery of cognitive tests (Table S6), the results indicated that boys scored consistently higher in mental arithmetic, and girls in reading comprehension and verbal reasoning. Across almost all permutations, girls also scored significantly higher in hidden arithmetic operators, geometric analogies, and hierarchical reading comprehension.

Girls had higher GPA (Table S7) across permutations. All single subjects except chemistry, handicraft, and social studies showed statistically significant sex differences (Table S8). Controlling for all other subjects, boys had higher grades in first foreign language (i.e., English), physics, geology, history, physical training, and mathematics, whereas girls had higher grades in native language (i.e., Finnish), biology, home economics, ethical studies, visual arts, music, and health education.

As optional subjects, girls had more often selected home economics, ethical studies, and music, whereas boys had selected handicraft and physical training more often (Table S9). Girls more commonly applied for high school as their first choice for secondary education (Table S10). Regarding vocational branches, girls applied more often to health care, beauty care, educational, 
natural resources, and traveling and catering, whereas boys applied more often to technical and traffic, economical, and IT branches (Tables S11 and S12). Regarding different types of high schools, girls applied more often to schools with a language or cultural emphasis, whereas boys more often applied to high schools with sports or social science emphasis.

\section{Research Question 1: Are there Sex Differences?}

Confirmatory results. Descriptive results for girls' and boys' mean FM scores, mean sex differences, and mean overlap coefficients across permutations are presented in Table 1. Girls were more feminine, and boys were more masculine across domains. The ordering of the sex differences from largest to smallest was: grade profiles $(D=1.48)$, personality facets $(D=0.95)$, personality factors $(D=0.86)$ and applied field of education $(D=0.77)$, values $(D=0.75)$ and optional subjects $(D=0.72)$, cognitive test profiles $(D=0.60)$ and GPA $(d=0.56)$, applying to academic/vocational track $(d=0.24)$, and general cognitive ability $(d=0.15)$.

Exploratory results. Pairwise comparisons of sex differences between domains with a $Q$-test (in metafor package; Viechtbauer, 2010) that accounted for the stochastic dependency of the estimates across permutations showed clear heterogeneity. Of all 45 comparisons, 40 showed a statistically significant difference, $p<.05$. Three groups emerged within which the magnitude of sex differences did not differ: personality factors and applied field of education, $Q(1)=2.44, p=.118$, cognitive test profiles and GPA, $Q(1)=0.27, p=.605$, and values, optional subjects, and applied field of education, for all three pairwise comparisons $p>.335$.

As requested by a reviewer, we also, for explorative purposes, calculated Mahalanobis' $D$ s for all variable sets. Furthermore, for personality factors and cognitive tests, we calculated $D_{\text {corrected }}$ which corrects the $D$-estimates for unreliability in the input variables ${ }^{1}$. We used $\omega_{\mathrm{t}}$ for personality factors and $\pi_{(2)}$ for cognitive tests as indicators of reliability. $D_{\mathrm{u}}$, the regularized version of Mahalanobis' $D$ was also calculated. Because all these calculations were done using the 
entire dataset (no cross-validation at any stage), we also obtained elastic net $D$ estimates computed from the entire dataset in order to allow for direct comparison and comparable levels of inflation due to overfitting. That is, cross-validation for the elastic net $D$ estimates was run within the training data with $k$-fold cross-validation, but the data was not split into training and testing sets for subsequent cross-validation.

All estimates from these exploratory analyses are reported in Table S16 in the SOM. There were few substantial differences between methods. Most notably $D_{\text {corrected }}$ for personality factors was 1.11 whereas elastic net $D$ and Mahalanobis' $D$ were both 0.89 (the mean estimate with the preregistered cross-validation method was 0.86 ). $D_{\text {corrected }}$ for cognitive tests was estimated at 0.76 , whereas elastic net $D(0.68)$ and Mahalanobis' $D(0.65)$ were only slightly lower (the mean estimate with the preregistered cross-validation method was 0.60 ). Elastic net $D$ estimates for personality facets with the entire data were somewhat higher $(D=1.13)$ than with the method that separated training and testing data $(D=0.89)$, which could be due to increased overfitting as the number of variables increases. For variable sets with fewer variables (there were 30 personality facets, whereas for other domains there were at most 16 variables) overfitting was less of a problem, as indicated by smaller differences in elastic net $D$ estimates (see Table S16).

Visual inspection of the distribution plots led us to realize that there might be notable differences in the within-sex variation of FM scores (see Table 2). Indeed, exploratory analysis showed that boys had significantly higher variance in FM-scores based on personal values $($ Variance Ratio $(\mathrm{VR})=1.30,95 \%$ CI $1.15-1.47)$, cognitive task profiles $(\mathrm{VR}=1.12,95 \%$ CI 1.01 - 1.23), grade profiles (VR $=1.17,95 \%$ CI $1.06-1.28)$, and applying to high school versus vocational institute $(\mathrm{VR}=1.29,95 \%$ CI $1.20-1.37)$.

To further illuminate these differences in variance, we categorized, within each domain, the proportions of girls and boys that were very gender typical, somewhat gender typical, indifferent, somewhat gender atypical, and very gender atypical. The predicted probabilities based 
on which the categories were created were, for boys (girls): .8-1.0 (0-.2), 6-.8 (.2-.4), .4-.6 (.4-.6), $.2-.4(.6-.8)$, and $0-.2(.8-1.0)$, respectively. This approach also allowed us to investigate whether, for instance, most boys within a domain were very boyish, or only somewhat boyish, and how many girlish boys there were. The mean probabilities for each category are presented in Table 3 . We also calculated how consistently the differences were observed across permutations to draw inferences about the significances of the between sex differences in gender typicality.

In the domain of personality, girls were more often very gender typical than boys were. This was observed for both factors (the mean proportion of very gender typical girls was .15; the corresponding number for boys was .09) and facets ( girls $=.20$, boys $=.11)$. Based on personality factors, boys were more often very gender atypical ( girls $=.01$, boys $=.03$ ), and based on personality facets boys were more often somewhat atypical (girls $=.12$, boys $=.18$ ) or indifferent $($ girls $=.27$, boys $=.33)$.

In the domain of personal values, girls were more often somewhat gender typical (girls = .46 , boys $=.31)$ and boys were more often somewhat gender atypical $($ girls $=.12$, boys $=.20)$.

Regarding general cognitive ability and cognitive test profiles, the typicality distributions were similar for girls and boys. For general cognitive ability, 99\% of girls and boys were categorized as indifferent, reflecting the small sex difference in this variable.

Reflecting the lower grade point average of boys, boys (who had very low GPA) were more often categorized as very gender typical than girls $($ girls $=.00$, boys $=.02)$. Gender typicality distributions based on the grade profile showed a steady increase towards the very typical category, which was the most common category among both girls and boys (girls $=.41$, boys $=.42)$. These distributions were not different between girls and boys.

Regarding optional subjects and applying for high school versus vocational institute, there were no sex differences in gender typicality. However, in terms of preferred field of education, boys 
were more often very gender typical $($ girls $=.10$, boys $=.21)$ and girls were more often somewhat gender typical $($ girls $=.26$, boys $=.07)$. The majority of the participants was, however, indifferent $($ girls $=.57$, boys $=.58)$.

\section{Research Question 2: Are narrower measures more informative regarding sex differences and gender?}

The predictive utility of each variable set is presented in Table 2. The first index gives the accuracy of correctly predicted sex in the testing data. The second index shows McFadden's pseudo-Rsquared metric obtained from logistic regressions in which FM-scores were used to predict sex. To examine the utility of the narrower measures, we added, within each domain, the narrower measures to logistic regression models that already included the broader measures and looked at whether this improved the models.

Broad personality factors (mean accuracy: 68.0\%) were almost as accurate as narrower facets $(69.4 \%)$ in predicting sex (Table 2). Nevertheless, the preregistered confirmatory tests did show that FM scores based on the facets improved predictive power across permutations (mean $\log$ odds $=0.18,95 \%$ CI $0.12-0.24$; the mean $/$ median of $-2 \times \log$ likelihood between the models across permutations was 10.20/10.18, $\mathrm{p}=.001$ for both). Facets also explained more variance than did domains; mean pseudo- $R^{2}$ s were $14.0 \%$ and $11.6 \%$, respectively.

Confirmatory tests showed that the battery of cognitive tasks was notably more accurate $(62.4 \%)$ and had more explanatory power (5.9\%) than did the general cognitive ability score $($ mean $\log$ odds $=0.23,95 \%$ CI $0.18-0.29$; the mean $/$ median of $-2 \times \log$ likelihood between the models across permutations was $34.72 / 34.43, \mathrm{p}<.001$ for both). Both accuracy $(52.4 \%)$ and predictive power $(0.4 \%)$ were very low for general cognitive ability.

Regarding academic achievement, confirmatory tests showed that FM-scores based on 16 separate subjects clearly outperformed GPA (mean log odds $=0.16,95 \%$ CI $0.15-0.18$; 
mean/median of $-2 \times \log$ likelihood between the models across permutations was $141.16 / 141.33, \mathrm{p}<$ .001 for both). This could be seen both from the former's higher predictive accuracy $(77.5 \% \mathrm{vs}$. $61.5 \%)$ and the larger proportion of variance explained (30.0\% vs. $5.4 \%)$.

Comparing a binary measure of preferences for academic level of secondary education (high school vs. vocational institute) with preferences for specific educational field (17 in all) showed a clear advantage for the latter, both in terms of percentage correct (55.6\% vs. $62.1 \%)$ and variance explained $(1.0 \%$ vs. $9.6 \%$; mean $\log$ odds $=0.16,95 \%$ CI $0.11-0.20$; the mean $/$ median of $-2 \times \log$ likelihood between the models across permutations was 59.04/59.13, $\mathrm{p}<.001$ for both). In sum, narrower measures outperformed broader measure in both psychological (personality and cognitive ability) and academic (academic achievement and educational preferences) domains.

\section{Research Question 3: Is Femininity-Masculinity Domain Specific or Correlated Across Domains?}

Confirmatory results. As alluded to above, after preregistering our research we realized that the zero-order correlations that we planned on presenting would be confounded by sex differences. To clarify, the measure of genderedness employed within the gender diagnosticity approach is computed based on sex differences in a set of attributes and is only meaningful when such differences exist (Lippa \& Connelly, 1990). This means that when looking at the associations of genderedness with other variables, these associations will by definition be confounded by sex. Also, correlations between two different measures of genderedness, computed in different domains from a different set of attributes, will invariably be confounded by sex. This means that despite research question 3 being preregistered, we will test it with methods - partial correlations that control for sex and separate analyses within sexes - that were not preregistered. It was necessary to use these 
methods to avoid confounding by sex (see exploratory results below; Ashton \& Lee, 2008; Twenge, 1999).

Although not, as it turned out, pertinent to the present research questions, but for the possible benefit to future meta-analyses in this area, we present, in accordance with the preregistered analysis plan, the zero-order correlations in Table S17 of the SOM. These zero-order correlations are, of course, higher than the partial and within-sex correlations that we report on, as they include variance that is attributable to the sex of the participant. On a cautionary note, it is important to keep in mind that the sex differences that are controlled for can be of biological, cultural, environmental, or any other conceivable origin - they are descriptive, not explanatory (Del Giudice, in press). That the relationships between FM-score computed from difference domains decrease from zero-order to partial correlations cannot therefore be interpreted as supporting any particular theory regarding the causes of sex- or gender-differences. We also emphasize that research question 3 does not ask whether boys and girls differ (this was covered by research questions 1 and 2). This makes the zero-order correlations, very much confounded by sex differences, rather useless. Instead, we ask whether a boy or a girl who is very boyish or girlish in one domain is likely to be more boyish or girlish also in other domains, and this question can be best answered by looking at partial correlations and within-sex correlations.

Exploratory results. The average partial correlations are presented in Table 4 and the within-sex correlations in Table 5. Partial correlations were calculated in two ways: only partialing out sex (partial) and partialing out sex as well as all the other FM-scores (unique partial). The comparison between these two are indicative of the degree to which the associations are conditionally independent, meaning that their association is dependent on other FM-scores. Because the narrower measures clearly outperformed the broader measures for personality, cognitive ability, grades, and school applications (research question 2), we selected the FM-scores derived from the narrower measures for examining the correlations. 
As indicated by the partial correlations, femininity-masculinity was correlated across domains. An exception to this was preference for field of education, which showed non-significant correlations with personality, values, and cognitive test profiles, although its associations with grade profiles and optional subjects were significant. The remaining twelve variable pairs were all positively correlated. These associations were, however, not very strong: the average partial correlation was $r^{\prime}=.09$. Clearly the strongest association was observed between personality FM scores and personal values FM scores, $r^{\prime}=.34$, with none of the other partial correlations stronger than $r^{\prime}=.12$.

The weakness of the observed partial correlations suggests that there may not be a general factor of genderedness, given that a factor should have substantial loadings (e.g., larger than .50) from each of its indicators. A one-factor, maximum likelihood exploratory factor analysis of the correlation matrix supported this interpretation: only personality FM scores and personal values FM scores loaded substantially on this factor (.56 and .59 , respectively), whereas cognitive test profiles (.16), grade profiles (.22), optional subjects (.12), and preferred field of education (.07) FM scores loaded only weakly. The factor accounted only $12.6 \%$ of the total variation in FM scores (95\% CI from $10.9 \%$ to $14.5 \%$ across separate analyses for each permutation). Results from confirmatory factor analysis, which allow for an interpretation similar to the exploratory factor analysis, can be found in SOM Table S18. Our results thus did not support the existence of a strong genderedness factor.

The absence of a "g-factor" of genderedness led us to interpret the results from a network perspective. This means that we do not assume a unitary common cause in the process that generates the data for various FM scores (as opposed to what latent factor model would assume; Christensen et al., 2020). More generally, the network approach to psychological characteristics understands these networks as complex dynamical systems of interacting variables (van Borkulo et al., 2017). Here, we use this approach to describe the unique and shared links in a network that 
consists of femininity-masculinity in six different domains. This will tell us whether certain femininity-masculinity scores are conditionally independent (their association can be explained by other FM-scores) or if they are uniquely associated beyond what can be explained by the other measured forms of femininity-masculinity. In addition, the general importance of each FM-score in the network can be estimated from its connectedness with other FM-scores (node strength:

Christensen et al., 2020). Finally, global network strength (van Borkulo et al., 2017) can be used to assess the degree of general dependency in the network and for comparison between the networks of boys and girls.

Although global network strength, calculated as the sum of the absolute associations in the entire network was statistically significantly different between partial (1.33) and unique partial (1.04) associations, $Q(1)=16.18, p<.001$, this difference was rather modest in size $(21.9 \%)$. This also showed in the unique partial correlations; only three of the twelve significant partial correlations were rendered non-significant when the other associations were controlled for (between personality and cognitive test profiles, personality and optional subjects, and values and optional subjects). This indicates that several pairs of FM-scores are uniquely associated with each other. The partial and unique partial correlation networks are depicted in Figure 1A-B.

The femininity-masculinity networks of boys and girls are illustrated in Figure 1C-F. The global strengths of the networks (boys $=1.50,95 \% \mathrm{CI}[1.19,1.81]$; girls $=1.27,95 \% \mathrm{CI}[1.02$, 1.55]) were not significantly different, $Q(1)=1.50, p=.220$. The reductions in global network strength when moving from partial to unique partial networks were similar for boys and girls $(22.7 \%$ and $11.9 \%$ drop for boys and girls, respectively, $Q(1)=1.49, p=.222)$. These analyses indicate that among both boys and girls, femininity-masculinity shows similarly weak generalizability across domains.

We next estimated the strength and centrality of single femininity-masculinity nodes (Costantini et al., 2015) in the partial network (Figure 1A) and in the within-sex networks (Figure 1 
panels $\mathrm{C}$ and $\mathrm{E}$ ). Node strengths are presented in Table 6. Femininity-masculinity in personality, values, and grade profiles were generally more central than femininity-masculinity in cognitive test profiles, optional school subjects, or field of preferred education. The node strength of values was also somewhat higher than that of grades, $Q(1)=4.27, p=.039$. A similar pattern was found in separate analyses of boys' and girls' femininity-masculinity networks. The only exception was that grade profile FM-scores were a stronger node among boys than among girls, $Q(1)=6.70, p=.010$.

We finally tested for sex differences in each pair of correlations (Table 5). There were three within-sex correlation estimates that differed between boys and girls. Among boys, the association between the FM-score based on personal values and the FM-score based on grades was stronger than among girls $(r=.16$ and $r=.05$, respectively, $p=.006)$. Boys also showed a stronger correlation between FM-scores based on grade profiles and preferred field of education $(r=.14$ and $r=.03$, respectively, $p=.007)$. Among girls, FM-scores based on optional subjects and FM-scores based on application were more strongly correlated than among boys $(r=.10$ and $r=.02, p=.034)$.

In sum, the correlations between FM-scores were weak and did not, despite being generally positive, suggest a general factor of genderedness. More detailed exploratory investigations from a network perspective revealed that femininity-masculinity in personality, personal values, and grade profiles are more central in the femininity-masculinity network than are cognitive test profiles, optional subjects, or preferred field of education. In addition, the grade profile was more central among boys than among girls, which was particularly evident in its stronger associations with femininity-masculinity scores based on personal values and preferred field of education.

\section{Discussion}

The present study of Finnish adolescents found that boys and girls differ in personality, values, cognitive aptitude profiles, grade profiles, optional school subjects, and in field of education applied for in secondary education. Very large sex differences were found in grade profiles, indicating that 
there are several academic subjects in which average girls (boys) perform notably better than average boys (girls) when controlling for performance in other subjects. The grade profiles showed clearly stronger sex differentiation than did personality traits, personal values, or cognitive test profiles, although these also showed medium to large sex differences.

Regarding our second preregistered research question, narrower measures of personality, cognitive ability, academic achievement, and preferences for secondary education outperformed broader measures of these constructs in the prediction of sex, leading to larger sex differences in narrow than in broad measures. Regarding personality, our results are consistent with previous work suggesting that narrow constructs can outperform broad traits in predicting various criterion outcomes (Seeboth \& Mõttus, 2018).

Our third preregistered research question asked whether femininity-masculinity in one domain was associated with femininity-masculinity in another domain. To answer this question, we-in contrast to the pre-registered method, which did not control for the confounding role of sex — employed sex-partialed and within-sex associations. Despite our results pointing to the existence of such associations, they were generally very weak, with the one exception that typically girlish (boyish) personality traits tended to go together with typically girlish (boyish) personal values. Because all the associations between domains were in the same direction, it was nevertheless possible to extract a single general factor via factor analysis. Given the extremely low loadings of all but personality and personal values variables on this factor and that it explained only $13 \%$ of the total variation in FM scores, we interpret our results as suggesting that there is no " $\mathrm{g}$ factor" of genderedness. We therefore employed the network perspective for further probing of the associations between domains.

On a more exploratory note, we investigated differences in the within-sex variation of FMscores and found that boys had significantly higher variance in FM-scores based on personal values, cognitive task profiles, grade profiles, and in applying to high school versus vocational institute. In 
terms of personality and values, there were more gender typical girls than there were boys. However, in terms of preferred field of education, there were more very gender typical boys.

The discussion focuses on the comparison of sex differences across domains and on what implications these findings have for future developmental studies. Academic achievement profiles are highlighted because they showed the largest sex differences and network analysis indicated their central role in within-sex femininity-masculinity associations.

\section{Overall Sex Differences in Adolescence}

Although boys and girls differed in all domains, the size of the gender gap varied widely between domains. The gender gap for personality was large $(D=0.95)$, and only slightly smaller than the gender gap reported on in a sample of Finnish adults (based on 30 personality facets, MacGiolla \& Kajonius, 2019, reported a gender gap of $D=1.16$ ). This suggests that overall sex difference in personality have almost plateaued in adolescence. Future studies should investigate whether overall sex differences in personality increase from childhood to adolescence, and if so, whether this is because initially small differences in given traits increase or because altogether new traits start showing sex differences.

Studies that have used multi-group covariance and mean structure analysis (Del Giudice et al., 2012; Kaiser, 2019; Kaiser et al., 2019) have reported notably larger sex differences than those we report on (often $D>2.0$ ). We could not employ latent variable modelling at the facet level because we did not have multi-item scales at that level. However, some theoretical consideration also advice against the use of latent variable modelling. First, it has recently been established that there is meaningful variation also at the lowest level of the personality structure; nuances or single personality scale items show unique longitudinal stability, heritability, interrater-agreement, and predictive utility (Mõttus et al., 2017, 2019). By focusing only on the common variance that is shared by a set of items, or relying on a parceling method that enforces the communality of input 
variables in latent variable models (Booth \& Irwing, 2011; Del Giudice et al., 2012), a large proportion of meaningful personality variation could be neglected. Also the present results testify to the importance of item level variation-facet-trained femininity-masculinity scores outperformed factor-trained femininity-masculinity scores in the prediction of sex, thus also showing larger sex differences than factors (see Mac Giolla \& Kajonius, 2019, for similar result). Second, latent variable modeling that aims to minimize measurement error makes strong assumptions regarding the data generation process. This approach could thus lead to severe bias and inconsistency in estimation, even in comparison to composite scales, which are also systematically biased (Rhemtulla et al., 2020). On the other hand, factor scores-sometimes computed in this type of research (Kaiser, 2019; Kaiser et al., 2019) —would have introduced other biases into our multivariate sex difference estimates (see Devlieger et al., 2016). In sum, although our predictive approach, because it does not account for measurement error, may give a somewhat attenuated estimate of sex differences, the bias is very likely to be smaller and certainly more consistent than the various types of bias that latent variable modeling procedures would have introduced - the former involve multiple decisions in the analytical pipeline (the use of items or parcels as inputs, the item parceling approach, examining model fit and change in fit following invariance constraints, model estimates or factor scores, factor scoring method etc.) and theoretically strong assumptions regarding the data generation process.

For the other domains besides personality and academic achievement, the present study was the first to describe the overall sex differences. Medium to large sex differences - but smaller than sex differences in personality - were found for values $(D=0.75)$, optionally selected school subjects $(D=0.72)$, preferred field of secondary education $(D=0.77)$, and cognitive test profiles $(D=0.60)$. Sex differences in univariate indices were also observed: large in GPA $(d=$ 0.57 , girls score higher), small in academic/vocational educational track $(d=0.24$, girls more often 
applied to academic track), and very small in general cognitive ability ( $d=0.15$, girls scored higher).

Regarding sex differences in personal values, previous studies have reported very small sex difference in single values (median $d=.15$ across values; Schwartz \& Rubel, 2005). Our results suggest that the overall gap in personal values is, by contrast, large. As in the domain of personality, the overall gap that we report on can be argued to be a better measure of sex differences than average univariate distances (Del Giudice, 2009; in press). This may be even more so in the case of personal values, as the ten basic values are not independent of each other but the total pattern of conflict and compatibility among the values forms a circular structure in which adjacent values reflect compatible motivations and opposing values reflect conflicting motivations (Schwartz, 1992). Schwartz and Rugel (2005) showed that cross-culturally, sex differences were most pronounced for power (men higher) and for benevolence (girls higher) values, and are results corroborate this finding in an adolescent sample. These two values were the largest contributors to the overall gender gap, followed by significant but smaller contributions from universalism (girls higher) and tradition (boys higher). The six remaining values did not reliably contribute to the overall sex difference in values. Future studies on the gender gap in values should employ the here presented methodology to adult populations, especially within a cross-cultural framework. Schwartz and Rubel (2005) reported that the largest sex differences in benevolence and power values were found in more egalitarian countries, and research on personality traits suggests that overall sex differences are larger in more egalitarian countries (MacGiolla \& Kajonius, 2019). Together these results suggest that the overall gender gap in values could also be largest in more egalitarian countries, something that could be investigated with the many large scale cross-cultural surveys that include values measures.

Although there were no meaningful sex differences in general cognitive ability, the performance profiles on cognitive tests did show a medium-to-large gender gap that indicated more 
sex differentiation than has usually been reported for single cognitive abilities (Halpern, 2011; Hedges \& Nowell, 1995; Miller \& Halpern, 2014; but see Lauer et al., 2019 and Lynn \& Irwing, 2002 for moderate differences in some mental rotation task variants and general knowledge, respectively). This implies that the common practice of summarizing across tasks tends to mask differences in how the sexes perform across a set of tasks (Johnson \& Bouchard, 2007). However, this difference should not be overstated. The magnitude of the sex difference in cognitive test profiles was similar to that of the sex difference in general academic achievement, GPA. Stated differently, the cognitive test score profile based on nine different cognitive tests gave as accurate a prediction of which sex any individual was as did the single GPA score (the accuracies were $62.44 \%$ and $61.66 \%$, respectively). Such predictions and comparisons are, of course, in some sense senseless, but do provide an intuitive metric about how (un)informative cognitive tests can be regarding sex.

The by far largest gender gap was found for grade profiles, which showed a very large sex difference $(D=1.48)$. Another recent cross-cultural study on a more limited set of achievement variables also indicated large overall sex differences ( $D s$ ranged between 0.75 and 1.26) (Stoet \& Geary, 2020). The expectancy-value model (Wigfield \& Eccles, 2000) has gained some traction in explaining sex-differences in grades. For instance, boys' lower reading grades have, in the absence of actual differences in reading skills, been explained by lower parental expectations and by lower self-assessed importance of reading (Heyder et al., 2017). Sex differences in parental expectations and self-assessed importance could vary from subject to subject (e.g., boys could be expected to perform better in physics), which could help explain the large overall gender gap in grade profiles. Importantly, the difference in grade profiles was much larger than the difference in cognitive test profiles, suggesting that something else than sex differences in cognitive ability are needed to explain the differences in grade profiles. Also speaking against differences in actual cognitive ability as explanations for the gender gap in grades, subjects that could be expected to rely heavily 
on the same set of cognitive abilities showed opposite direction associations with sex. For instance, both native language and history could be expected to rely heavily on reading skills, but high grades on the former were associated with being a girl and high grades on the latter with being a boy. Finally, the cognitive ability test was administered in a low-stakes research context, suggesting both that motivation will vary and that this will influence test scores (Duckworth et al., 2011; Kupiainen et al., 2014). This means that performance on a particular cognitive ability test might very much depend on the self-assessed importance of the skill being tested. In fact, in a different sample of Finnish 16-year-olds that completed a very similar battery of cognitive ability tests, controlling for self-reported effort and for amount of time spent responding rendered sex-differences insignificant (Vainikainen \& Hautamäki, 2018). Finally, sex differences in interests (Su et al., 2009) could independently add to investment in subject specific performance. This all adds up to suggesting that something else than cognitive ability profiles, be it parental expectations, self-assessed importance, and/or interest, is needed to explain the differences in grade profiles. Future research should investigate parental expectations and self-assessed importance of and interest in the academic subjects in order to evaluate whether these constructs could help explain the observed overall gender gap in grades.

Academic grade profiles allowed for rather accurate statistical predictions of sex (accuracy $77.53 \%$ ). Interestingly, this is very close to the classification of sex obtained with PISA scores and academic attitudes in 2009 and 2012 in Finland (Stoet \& Geary, 2020). This could have practical implications when grades and grade profiles are being assessed in application and selection processes. For instance, when assessing university applicants' academic grades as part of an ostensibly sex-blind selection procedure, the assessor might rather accurately guess the sex of the applicants. Future studies could investigate to what extent people can predict sex from grade profiles, and whether this is a skill that people improve in with experience. 
We report on sex difference at the very end of adolescents' primary education. An interesting question for future research is whether sex differences increase over the years. Given that the differences in grade profiles were so much larger than any other sex differences, these are likely to have, in part, developed during the school years, perhaps through at least some of the various processes outlined by the expectancy-value model (Wigfield \& Eccles, 2000). The very large sex differences also showed in the gender typicality examinations, with around $70 \%$ of boys and girls classified as at least somewhat gender typical in terms of their grade profiles. Of course, a substantial proportion was not gender typical, and sex differences in grade profiles should not be interpreted as being even close to taxonic (Carothers \& Reis, 2013).

In sum, sex difference were found across domains, and the magnitude of these overall differences was non-negligible, except for general cognitive ability. This strongly speaks against the idea that most psychological sex differences are small and meaningless (Hyde, 2014).

\section{The Gender Distributions of Boys and Girls Do Not Mirror Each Other}

Not only were mean scores different, but also variance in femininity-masculinity was different across sexes. Regarding personality traits and personal values, girls tended to be more gender typical than boys, with more girls classified as gender typical and more boys classified as somewhat gender atypical. Consistent with this, boys showed more within-sex variation in personal values. Moreover, boys showed more variation also in cognitive abilities and in academic grades, indicating that in these three domains, two randomly selected boys are more likely to be further apart from each other in terms of femininity-masculinity than would be two randomly selected girls.

The above described type of differences in intra-sex variability have been on a common theme in the literature on cognitive abilities, with both men (Hedges \& Nowell, 1995) and boys (Johnson et al., 2008; Strand et al., 2006) showing more intra-sex variability. Some research suggests that similar differences may exist in the realm of adult personality traits, with men showing 
higher intra-sex variability in informant (but not self-) reports of personality (Borkenau et al., 2013). By contrast, one of our more novel results is the larger intra-sex variance of boys in terms of personal values. In fact, the largest variance ratio that we found was for values $(\mathrm{VR}=1.30)$. For comparison, the variance ratio for human height is 1.11 (more variation among men: Lippa, 2009). This difference in intra-sex variance in values is also reflected in that girls were more often than boys classified as somewhat gender typical (46\% vs. $31 \%)$ and less often as somewhat gender atypical (12\% vs. $20 \%)$.

Within-sex heterogeneity in personal values may reflect sex differences in the loosenessrigidity of gender roles (Wood \& Eagly, 2015). Most girls had somewhat or very girlish values, whereas boys' values were more evenly spread across the boyish-girlish continuum. Given that gender-role expectations influence the development of values, these expectations may be more stringent for girls. For instance, girls may be expected to consider and value the well-being of other people (higher Benevolence, Universalism, lower Power), whereas such expectations may be lower for boys. In societies in which the sexes should, on paper, be equal, this type of abstract and difficult to measure gender role expectations can be an important source of continuing inequality.

Regarding preferences for field of secondary education, the above pattern is reversed. Boys were more gender typical: $21 \%$ of boys applied for a field classified as very gender typical, as opposed to $10 \%$ of girls. In none of the other domains except for grade profiles was there such a high proportion of the participant pool being classified as very typical. The simplest explanation is probably that a large proportion of boys prefer certain fields that are preferred primarily by other boys (another possible explanation, some form of "strategic" thinking in which boys consider what is realistic given their lower grades is less likely - participants could apply to as many as five different institutions, suggesting that their first choices, which we used, could be indicative of actual preferences). 
The above pattern, in which boys are in some sense freer in terms of personal values but more constrained in terms of educational preferences, is intriguing. Explanations referring to possibly stronger biological or genetic hard-wiring of values, as compared to educational preferences, would have one expect at least as strong between-sex differences in within-sex variance in personality traits. Personality, in which boys did not show greater intra-sex variability than did girls, overlaps with values but has been argued to be more hard-wired in terms of biological basis, with values being formed by both personality traits and by external influences, such as culture and life events (McCrae \& Costa, 2008). This implies that external influences allow boys more agency or freedom of choice in terms of what they value in life. However, when push comes to shove; that is, when sixteen-year-olds decide where to apply for secondary education, a decision they may perceive as being the most consequential decision of their life so far, boys end up behaving like other boys. Making this pattern even more intriguing, is that values, empirically associated with perceptions, attitudes, goals, and behaviors (Maio, 2010; Roccas \& Sagiv, 2010), would be expected to also be associated with important life choices. However, other than a study that showed that police officer recruits differ from the general population in terms of their values (Bardi et al., 2014), there is very little empirical evidence that would support a link between personal values and career choices.

The literature on gendered career choices and the distribution of men and women in the labor force has very much focused on women's lower interest in male-dominated occupations especially those in science, technology, engineering, and math (e.g., for a review on the gender gap in STEM occupations, see Wang \& Degol, 2017). Much less attention has been given to factors that contribute to men's disinterest and underrepresentation in female dominated occupations (ShenMiller \& Smiler, 2015). Our results suggest that it is boys or men who, despite showing more intrasex variation in their values, may be making the more gender stereotypical choice. This implies that other factors than personal values, such as culturally dictated occupational gender stereotypes 
(Forsman \& Barth, 2017) or the male-breadwinner norm (although this is in decline in Scandinavia, it is not a thing of the past, Edlund \& Öun, 2016; Leira, 2006) may constraint men's choices. A complimentary line of explanation could be that it is not so much the fields of education that matter, but boys' higher gender homophily: boys may, in part, make the career choices they make in order to be able to study and work together with other boys (men and boys have more gender homophilous networks and friendships than do women, e.g., Benenson et al., 2012; McPherson et al., 2001). This should be an interesting topic for future investigations.

\section{No Support for a g-Factor of Genderedness}

Our third research question concerned the generality of femininity-masculinity across psychological and educational domains. Although the associations between femininity-masculinity in one domain and femininity-masculinity in another domain were all positive, they were far too weak to suggest the existence of a unitary common source of variation shared between different femininitymasculinity scores. We therefore wish to emphasize that in the case of genderedness, despite reporting on a positive manifold, we do not believe that the present data in any way suggests the existence of a general factor of genderedness. There were, nevertheless, positive associations between the femininity-masculinity indices based on different domains, and alternative explanations of this positive manifold are needed.

We examined the associations between femininity-masculinity in different domains in terms of the network approach, which provides indices summarizing the role of single associations in the global network of associations without presupposing the existence of a general factor. With one exception, the femininity-masculinity scores based on different domains were weakly albeit positively correlated. The by far strongest association was found between self-reported personality traits and personal values. Although the strength of this association might partially reflect shared method variance, it is also likely to reflect substance. Previous research has shown that selfdirection values are strongly correlated with trait openness to experience and that benevolence 
values are strongly correlated with trait agreeableness (Parks-Leduc et al., 2015). Because these constructs overlap, also genderedness scores based on these constructs would be expected to overlap. Informant reports of personality would shed some light on the size of the overlap in the absence of variance attributable to the source of the ratings. Because femininity-masculinity in personality shows trait-like properties in terms of temporal stability and heritability (Loehlin et al., 2005), it could be expected to show trait-like properties also in terms of self-other agreement. As this tends to be rather high, variance attributable to the source of the ratings may not have distorted our results that much.

Personality and values were also the more central nodes in the femininity-masculinity networks. Perhaps more interestingly, in terms of not owing its centrality to construct overlap or method variance, grade profile femininity-masculinity was also central, especially in the femininitymasculinity network of boys. The correlational evidence that we have does not allow for inferences regrading causality but, its connectedness with other forms of femininity-masculinity suggests that academic grade profiles would be a good place to start the search for the more important determinants and consequences of gender typicality. Grade profiles are not only relevant for understanding sex differences, but also for understanding within-sex femininity-masculinity associations.

Although the bivariate associations between boyishness (girlishness) in one domain with boyishness (girlishness) in another domain are weak, they are consistently found across domains, suggesting some degree of generalizability. At least some of the unique associations could allow for substantive interpretations. For example, boyish (girlish) grade profiles and boyish educational preferences could have a mutual cause and/or they could reciprocally reinforce each other. Also differences between boys' and girls' networks could have meaningful interpretations. Femininitymasculinity in grades and values were more strongly associated among boys than among girls. This could, again, speak to sex differences in the looseness-rigidity of gender roles (Wood \& Eagly, 
2015) and perhaps also to different expectations regarding school performance; shrugging our collective shoulders in resignation and saying "boys will be boys" when it comes to performance in some subjects, such as reading, may set the bar much too low (Kimmel, 2006). On the most general level, the stronger association between grades and values in boys' as compared to girls' networks could be explained by the greater freedom of boys; both to endorse whichever values they wish to endorse and to perform less consistently across school subjects.

The unique associations (associations in which variance in all the other domains was controlled for) between femininity-masculinity scores were not much weaker than the associations in which only sex was controlled for. This again speaks against a common source of variation in femininity-masculinity across domains. That different FM-scores are not redundant suggests that a general cross-domain form of femininity-masculinity is best understood as a complex dynamical system of weakly interacting domain-specific indices of femininity-masculinity (van Borkulo et al., 2017). Therefore, rather than aiming for parsimony in understanding femininity-masculinity, future research should first focus on comprehensively covering various forms of femininity-masculinity. The network approach to gender diagnosticity would then allow for examining the unique components and communities that such a system would be comprised of (Christensen et al., 2020). Despite the absence of a general factor of genderedness, there could be communities comprised of a limited set of certain forms of femininity-masculinity. For example, separately calculating FMscores for each of the five personality factors from self- and informant-reports would allow for the examining the possibility of finding a community that could be labelled "femininity-masculinity in personality" and/or whether some scores would also be uniquely associated with femininitymasculinity in non-personality domains. 


\section{Limitations and Future Directions}

Although the administered battery of cognitive tests did include nine different measures, it may have left out specific areas of cognitive ability. For example, some tests for which some of the larger sex differences have been documented, were not included. A recent meta-analysis suggests that the sex difference at 16 could be roughly between $d=0.40$ and $d=0.60$ for mental rotation (Lauer et al., 2019), and a sex difference of similar magnitude was reported for general knowledge in a study of undergraduates in the UK (Lynn \& Irwing, 2002). However, because mental rotation and general knowledge presumably show at least moderate correlations with some, if not all, of the cognitive tests that we did administer, these sex difference cannot in any straightforward way be added to the multivariate estimate we obtained. Nevertheless, sex differences in any domain should ideally be studied using the most comprehensive and broad set of variables, with the emphasis on variables that have been previously known to show sex differences. This applies not only to cognitive tests, but also to other domains, such as personality and values, of which the latter was measured with only ten items.

Another limitation is that NCS personality items used in the present study were single item measure of personality facets. Not all facets, let alone narrower nuances, are included in this type of measure that has been designed top-down with the intention to measure broad domains such as the Big Five. Personality taxonomies that take a bottom-up approach (e.g., Condon et al., 2020) would include a richer set of personality nuances and facets, which could describe larger multivariate sex differences and allow for better predictions of sex.

Relatedly, irrespective of whether a prediction-focused strategy or a more explanatory approach is used, it is important that the measurement scales used in the multivariate set are reliable. Even when classical test theory reliability indices do not apply, it is important in other ways to show that the input variables are consistent (Christensen et al., 2020; McCrae, 2015). In the present study, such indices were not available for all variables (value items and personality facets) 
and reliabilities on some scales were quite low (openness to experience, reading comprehension: multiple-choice, and verbal proportional reasoning) which may have led to some inaccuracies in estimation. Comparisons of disattenuated Mahalanobis' $D$ estimates with other estimates nevertheless indicated that the degree of possible underestimation due to unreliability was small (see SOM Table S16).

Regarding underlying causes, it is important to note that our results are merely descriptive, not explanatory, in a similar way that sex differences are (Del Giudice, in press). They do not speak to questions of why the sexes differ in genderedness or why certain femininity-masculinity scores are correlated and others are not. Our results fit social role theory just as well as evolutionary views, as both social roles and biological factors can have contributed to sex differences and to the genderedness of particular individuals.

Given that there is no general factor of genderedness, and interesting question for future research could be which domains are most relevant for determining whether someone is perceived as girlish or boyish. That is, what constitutes girlishness or boyishness in the eyes of the perceiver? It could be one of the domains that we assessed, or it could be something different, such as playing style or appearance. Investigating associations between girlishness and boyishness in different life domains, and determining which domains are central in determining how the person is perceived, should be interesting questions for future research.

Of course, perceptions of girlishness and boyishness are likely to vary across cultures, cohorts, and perceivers. Furthermore, and even more pertinent to the present research, sex differences and gender roles also vary across cultures. In Finland, sex differences in many of the characteristics that we investigated are particularly pronounced as compared to other countries. For instance, sex differences in personality traits (Mac Giolla \& Kajonius, 2019), as well as in PISA performance and career choices (Stoet \& Geary, 2018) are larger in Finland than in most other cultures. To what extent our findings regarding sex difference, gender typicality, and the lack of a 
general factor of genderedness replicate in other cultures should be interesting questions for future research.

\section{Conclusions}

The present research updates the gender diagnosticity approach by employing penalized logistic regression to estimate multivariate sex differences based on both binary and continuous variables. The method allows for the robust and seamless integration of sex difference and gender typicality examinations, as well as various types of between sex comparisons regarding the variability and connectedness of different indices of femininity-masculinity. The methods introduced here can be applied in future studies that seek to investigate the development of sex differences and genderedness in multivariate frameworks.

Besides the methodological advancements, the present research, being the first to investigate the associations between gender typicality in different domains, also has several substantive contributions. First off, we estimate the magnitude of adolescents' sex differences in various psychological characteristics and in educational attainment and aspirations. Our results show that the magnitude of these differences varies a lot from domain to domain, and it will be highly interesting to compare the size of the differences that we report on with differences found in other age groups or in other cultures. Second, our results suggest that gender typicality, a theme that to date has not received the same research attention as sex differences, could offer important insights into the role of gender in shaping people's lives. For instance, speaking to the normative pressures of gender roles, girls reported more gender typical personal values, but boys were more often gender typical in terms of educational choices. Third, narrower measures, especially grade profiles, were generally very good at predicting sex, suggesting a potential risk for sex-bias even in sex-blind evaluation contexts. Finally, our results suggest that there is no such thing a typical boy or a girl: boyishness is one domain, such as personality, is only very weakly related to boyishness in other 
domains, such as cognitive profile or academic grades. When discussing boyishness or girlishness, a specifying clause giving more information should always be added.

\section{Data accessibility statement}

In agreement with the Education Department of the city where the study was conducted, the data are stored on a private university network to which researchers can gain access only by application and no part of the data are allowed to be downloaded from that network to another location. Doing so would be a breach of contract. Thus, the data are not available. Materials and analysis scripts with related results output are available at https://osf.io/gpcyh/.

\section{References}

Ashton, M. C., \& Lee, K. (2008). Gender-Related Occupational Interests Do Not Define a Masculinity-Femininity Factor. Journal of Individual Differences, 29(1), 25-34. https://doi.org/10.1027/1614-0001.29.1.25

Bardi, A., Buchanan, K. E., Goodwin, R., Slabu, L., \& Robinson, M. (2014). Value stability and change during self-chosen life transitions: Self-selection versus socialization effects. Journal of Personality and Social Psychology, 106(1), 131-147. https://doi.org/10.1037/a0034818

Baumert, A., Schmitt, M., Perugini, M., Johnson, W., Blum, G., Borkenau, P., Costantini, G., Denissen, J. J. A., Fleeson, W., \& Grafton, B. (2017). Integrating personality structure, personality process, and personality development. European Journal of Personality, 31(5), 503-528. https://doi.org/10.1002/per.2115

Benenson, J. F., Quinn, A., \& Stella, S. (2012). Boys affiliate more than girls with a familiar samesex peer. Journal of Experimental Child Psychology, 113(4), 587-593. https://doi.org/10.1016/j.jecp.2012.08.003 
Booth, T., \& Irwing, P. (2011). Sex differences in the 16PF5, test of measurement invariance and mean differences in the US standardisation sample. Personality and Individual Differences, 50(5), 553-558. https://doi.org/10.1016/j.paid.2010.11.026

Borkenau, P., McCrae, R. R., \& Terracciano, A. (2013). Do men vary more than women in personality? A study in 51 cultures. Journal of Research in Personality, 47(2), 135-144. https://doi.org/10.1016/j.jrp.2012.12.001

van Borkulo, C. D., Boschloo, L., Kossakowski, J. J., Tio, P., Schoevers, R. A., Borsboom, D., \& Waldorp, L. J. (2017). Comparing network structures on three aspects: A permutation test.

van Buuren, S., \& Groothuis-Oudshoorn, K. (2011). mice: Multivariate imputation by chained equations in R. Journal of Statistical Software, 45(3). https://doi.org/10.18637/jss.v045.i03 Carothers, B. J., \& Reis, H. T. (2013). Men and women are from Earth: Examining the latent structure of gender. Journal of Personality and Social Psychology, 104(2), 385-407. https://doi.org/10.1037/a0030437

Cheng, Y., Yuan, K.-H., \& Liu, C. (2012). Comparison of Reliability Measures Under Factor Analysis and Item Response Theory. Educational and Psychological Measurement, 72(1), 52-67. https://doi.org/10.1177/0013164411407315

Christensen, A. P., Golino, H., \& Silvia, P. J. (2020). A psychometric network perspective on the validity and validation of personality trait questionnaires. European Journal of Personality, 34(6), 1095-1108. https://doi.org/10.1002/per.2265

Cohen, J. (1960). A coefficient of agreement for nominal scales. Educational and Psychological Measurement, 20(1), 37-46. https://doi.org/10.1177/001316446002000104

Colom, R., García, L. F., Juan-Espinosa, M., \& Abad, F. J. (2002). Null sex differences in general intelligence: Evidence from the WAIS-III. The Spanish Journal of Psychology, 5(1), 29-35. https://doi.org/10.1017/S1138741600005801 
Condon, D. M., Wood, D., Mõttus, R., Booth, T., Costantini, G., Greiff, S., Johnson, W., Lukaszewski, A., Murray, A., Revelle, W., Wright, A. G. C., Ziegler, M., \& Zimmermann, J. (2020). Bottom Up Construction of a Personality Taxonomy. European Journal of Psychological Assessment, 36(6), 923-934. https://doi.org/10.1027/1015-5759/a000626

Costa, P. T., \& McCrae, R. R. (1992). Revised NEO Personality Inventory (NEO-PI-R) and NEO Five-Factor Inventory (NEO-FFI) professional manual. Psychological Assessment Resources.

Costantini, G., Epskamp, S., Borsboom, D., Perugini, M., Mõttus, R., Waldorp, L. J., \& Cramer, A. O. J. (2015). State of the aRt personality research: A tutorial on network analysis of personality data in R. Journal of Research in Personality, 54, 13-29. https://doi.org/10.1016/j.jrp.2014.07.003

Del Giudice, M. (2009). On the real magnitude of psychological sex differences. Evolutionary Psychology, 7(2), 147470490900700220. https://doi.org/10.1177/147470490900700209

Del Giudice, M. (2013). Multivariate misgivings: Is D a valid measure of group and sex differences? Evolutionary Psychology, 11(5), 147470491301100500. https://doi.org/10.1177/147470491301100511

Del Giudice, M. (in press). Measuring sex differences and similarities. In D. P. VanderLaan \& W. I. Wong (Eds.), Gender and sexuality development: Contemporary theory and research. Springer.

Del Giudice, M., Booth, T., \& Irwing, P. (2012). The distance between mars and venus: Measuring global sex differences in personality. PLOS ONE, 7(1), e29265. https://doi.org/10.1371/journal.pone.0029265

Devlieger, I., Mayer, A., \& Rosseel, Y. (2016). Hypothesis Testing Using Factor Score Regression: A Comparison of Four Methods. Educational and Psychological Measurement, 76(5), 741770. https://doi.org/10.1177/0013164415607618 
Demetriou, A., Pachaury, A., Metallidou, Y., \& Kazi, S. (1996). Universals and specificities in the structure and of quantitative-relational thought: A cross-cultural study in Greece and India. International Journal of Behavioral Development, 19(2), 255-290.

https://doi.org/10.1080/016502596385785

Duckworth, A. L., Quinn, P. D., Lynam, D. R., Loeber, R., \& Stouthamer-Loeber, M. (2011). Role of test motivation in intelligence testing. Proceedings of the National Academy of Sciences, 108(19), 7716-7720. https://doi.org/10.1073/pnas.1018601108

Edlund, J., \& Öun, I. (2016). Who should work and who should care? Attitudes towards the desirable division of labour between mothers and fathers in five European countries. Acta Sociologica, 59(2), 151-169. https://doi.org/10.1177/0001699316631024

Forsman, J. A., \& Barth, J. M. (2017). The effect of occupational gender stereotypes on men's interest in female-dominated occupations. Sex Roles, 76(7-8), 460-472. https://doi.org/10.1007/s11199-016-0673-3

Freudenthaler, H. H., Spinath, B., \& Neubauer, A. C. (2008). Predicting school achievement in boys and girls. European Journal of Personality, 22(3), 231-245. https://doi.org/10.1002/per.678

Friedman, J., Hastie, T., \& Tibshirani, R. (2010). Regularization paths for generalized linear models via coordinate descent. Journal of Statistical Software, 33(1), 1-22. https://doi.org/ 10.18637/jss.v033.i01

Gelman, A., \& Loken, E. (2014). The Statistical Crisis in Science. American Scientist, 102(6), 460465.

Hautamäki, J. (1989). The application of a Rasch model on Piagetian measures of stages of thinking. In P. Adey, J. Bliss, J. Head, \& M. Shayer (Eds.), Adolescent development and school science (pp. 342-349). Falmer Press. 
Hedges, L. V., \& Nowell, A. (1995). Sex differences in mental test scores, variability, and numbers of high-scoring individuals. Science, 269(5220), 41-45. https://doi.org/10.1126/science.7604277

Heyder, A., Kessels, U., \& Steinmayr, R. (2017). Explaining academic-track boys’ underachievement in language grades: Not a lack of aptitude but students' motivational beliefs and parents' perceptions? British Journal of Educational Psychology, 87(2), 205223. https://doi.org/10.1111/bjep.12145

Hosenfeld, B., van den Boom, D. C., \& Resing, W. C. M. (1997). Constructing geometric analogies for the longitudinal testing of elementary school children. Journal of Educational Measurement, 34(4), 367-372. https://doi.org/10.1111/j.1745-3984.1997.tb00524.x

Hyde, J. S. (2005). The gender similarities hypothesis. American Psychologist, 60(6), 581-592. https://doi.org/10.1037/0003-066X.60.6.581

Hyde, J. S. (2014). Gender similarities and differences. Annual Review of Psychology, 65(1), 373398. https://doi.org/10.1146/annurev-psych-010213-115057

Ilmarinen, V. J. (2021). multid: Multivariate Difference Between Two Groups (0.2.0) [Computer software]. https://CRAN.R-project.org/package=multid

Johnson, W., \& Bouchard, T. J. (2007). Sex differences in mental abilities: G masks the dimensions on which they lie. Intelligence, 35(1), 23-39. https://doi.org/10.1016/j.intell.2006.03.012

Johnson, W., Carothers, A., \& Deary, I. J. (2008). Sex differences in variability in general intelligence: A new look at the old question. Perspectives on Psychological Science, 3(6), 518-531. https://doi.org/10.1111/j.1745-6924.2008.00096.x

Kaiser, T., Del Giudice, M., \& Booth, T. (2019). Global sex differences in personality: Replication with an open online dataset. Journal of Personality. https://doi.org/10.1111/jopy.12500 
Kaiser, T. (2019). Nature and evoked culture: Sex differences in personality are uniquely correlated with ecological stress. Personality and Individual Differences, 148, 67-72. https://doi.org/10.1016/j.paid.2019.05.011

Kimmel, M. (2006). A war against boys? Dissent, 54(4), 65-70.

\section{https://doi.org/10.1353/dss.2006.0002}

Konstabel, K., Lönnqvist, J. E., Walkowitz, G., Konstabel, K., \& Verkasalo, M. (2012). The 'Short Five' (S5): Measuring personality traits using comprehensive single items. European Journal of Personality, 26(1), 13-29. https://doi.org/10.1002/per.813

Kupiainen, S., Vainikainen, M.-P., Marjanen, J., \& Hautamäki, J. (2014). The role of time on task in computer-based low-stakes assessment of cross-curricular skills. Journal of Educational Psychology, 106(3), 627-638. https://doi.org/10.1037/a0035507

Lauer, J. E., Yhang, E., \& Lourenco, S. F. (2019). The development of gender differences in spatial reasoning: A meta-analytic review. Psychological Bulletin, 145(6), 537-565. https://doi.org/10.1037/bul0000191

Legewie, J., \& DiPrete, T. A. (2012). School context and the gender gap in educational achievement. American Sociological Review, 77(3), 463-485. https://doi.org/10.1177/0003122412440802

Lehto, J., Scheinin, P., Kupiainen, S., \& Hautamaki, J. (2001). National survey of reading comprehension in Finland. Journal of Research in Reading, 24(1), 99-110. https://doi.org/10.1111/1467-9817.00135

Leira, A. (2006). Parenthood change and policy reform in Scandinavia, 1970s-2000s. In A. L. Ellingsæter \& A. Leira, Politicising parenthood in Scandinavia. Gender relations in welfare states (pp. 27-52). Policy Press.

Leversen, I., Torsheim, T., \& Samdal, O. (2012). Gendered leisure activity behavior among Norwegian adolescents across different socio-economic status groups. International Journal 
of Child, Youth and Family Studies, 3(4), 355-375.

https://doi.org/10.18357/ijcyfs34201211482

Lindeman, M., \& Verkasalo, M. (2005). Measuring values with the Short Schwartz's Value Survey. Journal of Personality Assessment, 85(2), 170-178.

https://doi.org/10.1207/s15327752jpa8502_09

Lippa, R. A. (1991). Some psychometric characteristics of gender diagnosticity measures:

Reliability, validity, consistency across domains, and relationship to the Big Five. Journal of Personality and Social Psychology, 61(6), 1000-1011. https://doi.org/10.1037/0022-

3514.61.6.1000

Lippa, R. A. (1998). Gender-related individual differences and the structure of vocational interests: The importance of the people-things dimension. Journal of Personality and Social Psychology, 74(4), 996-1009. https://doi.org/10.1037/0022-3514.74.4.996

Lippa, R. A. (2005). Subdomains of gender-related occupational interests: Do they form a cohesive bipolar m-f dimension? Journal of Personality, 73(3), 693-730. https://doi.org/10.1111/j.1467-6494.2005.00326.x

Lippa, R. A. (2009). Sex differences in sex drive, sociosexuality, and height across 53 nations: Testing evolutionary and social structural theories. Archives of Sexual Behavior, 38(5), 631651. https://doi.org/10.1007/s10508-007-9242-8

Lippa, R. A. (2010). Gender differences in personality and interests: When, where, and why? Social and Personality Psychology Compass, 4(11), 1098-1110. https://doi.org/10.1111/j.17519004.2010.00320.x

Lippa, R. A., \& Connelly, S. (1990). Gender diagnosticity: A new Bayesian approach to genderrelated individual differences. Journal of Personality and Social Psychology, 59(5), 10511065. https://doi.org/10.1037/0022-3514.59.5.1051 
Lippa, R. A., \& Hershberger, S. (1999). Genetic and environmental influences on individual differences in masculinity, femininity, and gender diagnosticity: Analyzing data from a classic twin study. Journal of Personality, 67(1), 127-155. https://doi.org/10.1111/14676494.00050

Loehlin, J. C., Jönsson, E. G., Gustavsson, J. P., Stallings, M. C., Gillespie, N. A., Wright, M. J., \& Martin, N. G. (2005). Psychological masculinity-femininity via the gender diagnosticity approach: Heritability and consistency across ages and populations. Journal of Personality, 73(5), 1295-1320. https://doi.org/10.1111/j.1467-6494.2005.00350.x

Logie, R. H., \& Pearson, D. G. (1997). The inner eye and the inner scribe of visuo-spatial working memory: Evidence from developmental fractionation. European Journal of Cognitive Psychology, 9(3), 241-257. https://doi.org/10.1080/713752559

Lönnqvist, J. E., Verkasalo, M., \& Vainikainen, M. P. (2011). Parent-teacher agreement on 7-Yearold children's personality. European Journal of Personality, 25(5), 306-316. https://doi.org/10.1002/per.791

Lönnqvist, J. E., \& Ilmarinen, V. J. (2021). Using a continuous measure of genderedness to assess sex differences in the attitudes of the political elite. Political Behavior. https://doi.org/10.1007/s11109-021-09681-2

Lynn, R., \& Irwing, P. (2002). Sex differences in general knowledge, semantic memory and reasoning ability. British Journal of Psychology, 93(4), 545-556. https://doi.org/10.1348/000712602761381394

Lyytinen, S., \& Lehto, J. E. (1998). Hierarchy rating as a measure of text macroprocessing: Relationship with working memory and school achievement. Educational Psychology, 18(2), 157-169. https://doi.org/10.1080/0144341980180202 
Mac Giolla, E., \& Kajonius, P. J. (2019). Sex differences in personality are larger in gender equal countries: Replicating and extending a surprising finding. International Journal of Psychology, 54(6), 705-711. https://doi.org/10.1002/ijop.12529

Magnusson, K. (2021). Interpreting Cohen's d effect size: An interactive visualization (Version 2.5.0) [Web App]. R Psychologist. https://rpsychologist.com/cohend/

Mahalanobis, P. C. (1936). On the generalized distance in statistics. Proceedings of the National Institute of Science, Calcutta, 2, 49-55.

Mahalik, J. R., Lombardi, C. M., Sims, J., Coley, R. L., \& Lynch, A. D. (2015). Gender, maletypicality, and social norms predicting adolescent alcohol intoxication and marijuana use. Social Science \& Medicine, 143, 71-80. https://doi.org/10.1016/j.socscimed.2015.08.013

Maio, G. R. (2010). Mental representations of social values. In M. P. Zanna (Ed.), Advances in experimental social psychology (Vol. 42, pp. 1-43). Academic Press. https://doi.org/10.1016/S0065-2601(10)42001-8

McCrae, R. R. (2015). A more nuanced view of reliability: Specificity in the trait hierarchy. Personality and Social Psychology Review, 19(2), 97-112. https://doi.org/10.1177/1088868314541857

McCrae, R. R., \& Costa, P. T. (2008). The Five-Factor Theory of personality. In O. P. John, R. W. Robins, \& L. A. Pervin (Eds.), Handbook of personality (3rd ed., pp. 159-181). Guilford Press.

McNeish, D. M. (2015). Using lasso for predictor selection and to assuage overfitting: A method long overlooked in behavioral sciences. Multivariate Behavioral Research, 50(5), 471-484. https://doi.org/10.1080/00273171.2015.1036965

McPherson, M., Smith-Lovin, L., \& Cook, J. M. (2001). Birds of a feather: Homophily in social networks. Annual Review of Sociology, 27(1), 415-444.

https://doi.org/10.1146/annurev.soc.27.1.415 
Miller, D. I., \& Halpern, D. F. (2014). The new science of cognitive sex differences. Trends in Cognitive Sciences, 18(1), 37-45. https://doi.org/10.1016/j.tics.2013.10.011

Mõttus, R., Kandler, C., Bleidorn, W., Riemann, R., \& McCrae, R. R. (2017). Personality traits below facets: The consensual validity, longitudinal stability, heritability, and utility of personality nuances. Journal of Personality and Social Psychology, 112(3), 474-490. https://doi.org/10.1037/pspp0000100

Mõttus, R., \& Rozgonjuk, D. (2019). Development is in the details: Age differences in the Big Five domains, facets, and nuances. Journal of Personality and Social Psychology, 120(4), 10351048. https://doi.org/10.1037/pspp0000276

Mõttus, R., Sinick, J., Terracciano, A., Hřebíčková, M., Kandler, C., Ando, J., Mortensen, E. L., Colodro-Conde, L., \& Jang, K. L. (2019). Personality characteristics below facets: A replication and meta-analysis of cross-rater agreement, rank-order stability, heritability, and utility of personality nuances. Journal of Personality and Social Psychology, 117(4), 35-50. https://doi.org/10.1037/pspp0000202

Mõttus, R., Wood, D., Condon, D. M., Back, M. D., Baumert, A., Costantini, G., Epskamp, S., Greiff, S., Johnson, W., Lukaszewski, A., Murray, A., Revelle, W., Wright, A. G. C., Yarkoni, T., Ziegler, M., \& Zimmermann, J. (2020). Descriptive, Predictive and Explanatory Personality Research: Different Goals, Different Approaches, but a Shared Need to Move beyond the Big Few Traits. European Journal of Personality, 34(6), 11751201. https://doi.org/10.1002/per.2311

Nosek, B. A., Ebersole, C. R., DeHaven, A. C., \& Mellor, D. T. (2018). The preregistration revolution. Proceedings of the National Academy of Sciences, 115(11), 2600-2606. https://doi.org/10.1073/pnas.1708274114

Ozer, D. J., \& Reise, S. P. (1994). Personality assessment. Annual Review of Psychology, 45, 357388. 
Parks-Leduc, L., Feldman, G., \& Bardi, A. (2015). Personality traits and personal values: A metaanalysis. Personality and Social Psychology Review, 19(1), 3-29. https://doi.org/10.1177/1088868314538548

Paunonen, S. V., \& Ashton, M. C. (2001). Big Five factors and facets and the prediction of behavior. Journal of Personality and Social Psychology, 81(3), 524-539. https://doi.org/10.1037/0022-3514.81.3.524

Pelletier, R., Ditto, B., \& Pilote, L. (2015). A composite measure of gender and its association with risk factors in patients with premature acute coronary syndrome: Psychosomatic Medicine, 77(5), 517-526. https://doi.org/10.1097/PSY.0000000000000186

Pohar, M., Blas, M., \& Turk, S. (2004). Comparison of logistic regression and linear discriminant analysis: A simulation study. Metodološki Zvezki, 1(1), 143-161.

Pozzebon, J. A., Visser, B. A., \& Bogaert, A. F. (2015). Vocational interests, personality, and sociosexuality as indicators of a general masculinity/femininity factor. Personality and Individual Differences, 86, 291-296. https://doi.org/10.1016/j.paid.2015.06.019

Pöysä, S., \& Kupiainen, S. (Eds.). (2018). Tytöt ja pojat koulussa-Miten selättää poikien heikko suoriutuminen [Girls and boys in school - How to contend with the poor performance of boys]. Prime Minister's Office.

Press, S. J., \& Wilson, S. (1978). Choosing between logistic regression and discriminant analysis. Journal of the American Statistical Association, 73(364), 699-705. https://doi.org/10.1080/01621459.1978.10480080

R Core Team. (2019). $R$ : A language and environment for statistical computing. https://www.Rproject.org/

Realo, A., Allik, J., Lönnqvist, J. E., Verkasalo, M., Kwiatkowska, A., Kööts, L., Kütt, M., Barkauskiene, R., Laurinavicius, A., \& Karpinski, K. (2009). Mechanisms of the national character stereotype: How people in six neighbouring countries of Russia describe 
themselves and the typical Russian. European Journal of Personality, 23(3), 229-249. https://doi.org/10.1002/per.719

Revelle, W., \& Condon, D. M. (2019). Reliability from $\alpha$ to $\omega$ : A tutorial. Psychological Assessment, 31(12), 1395-1411. https://doi.org/10.1037/pas0000754

Rhemtulla, M., van Bork, R., \& Borsboom, D. (2020). Worse than measurement error: Consequences of inappropriate latent variable measurement models. Psychological Methods, 25(1), 30-45. https://doi.org/10.1037/met0000220

Roccas, S., \& Sagiv, L. (2010). Personal values and behavior: Taking the cultural context into account. Social and Personality Psychology Compass, 4(1), 30-41. https://doi.org/10.1111/j.1751-9004.2009.00234.x

Ross, J. D., \& Ross, C. M. (1979). Ross test of higher cognitive processes. Academic Therapy. Schneider, W. J., \& McGrew, K. S. (2012). The Cattell-Horn-Carroll model of intelligence. In D. P. Flanagan \& P. L. Harrison (Eds.), Contemporary intellectual assessment: Theories, tests, and issues (p. 99-144). The Guilford Press.

Schwartz, S. H. (1992). Universals in the content and structure of values: Theoretical advances and empirical tests in 20 countries. In M. P. Zanna (Ed.), Advances in experimental social psychology (Vol. 25, pp. 1-65). Academic Press. https://doi.org/10.1016/S00652601(08)60281-6

Schwartz, S. H. (1996). Value priorities and behavior: Applying a theory of integrated value systems. In C. Seligman, J. M. Olson, \& M. P. Zanna (Eds.), The psychology of values (pp. 1-24). Lawrence Erlbaum Associates, Inc.

Schwartz, S. H., \& Rubel, T. (2005). Sex differences in value priorities: Cross-cultural and multimethod studies. Journal of Personality and Social Psychology, 89(6), 1010-1028. https://doi.org/10.1037/0022-3514.89.6.1010 
Seeboth, A., \& Mõttus, R. (2018). Successful explanations start with accurate descriptions: Questionnaire items as personality markers for more accurate predictions. European Journal of Personality, 32(3), 186-201. https://doi.org/10.1002/per.2147

Shen-Miller, D., \& Smiler, A. P. (2015). Men in female-dominated vocations: A rationale for academic study and introduction to the special issue. Sex Roles, 72(7-8), 269-276. https://doi.org/10.1007/s11199-015-0471-3

Sternberg, R. J., Castejón, J. L., Prieto, M. D., Hautamäki, J., \& Grigorenko, E. L. (2001). Confirmatory factor analysis of the Sternberg Triarchic Abilities Test in three international samples. European Journal of Psychological Assessment, 17(1), 1-16. https://doi.org/10.1027//1015-5759.17.1.1

Stoet, G., \& Geary, D. C. (2015). Sex differences in academic achievement are not related to political, economic, or social equality. Intelligence, 48, 137-151. https://doi.org/10.1016/j.intell.2014.11.006

Stoet, G., \& Geary, D. C. (2018). The gender-equality paradox in science, technology, engineering, and mathematics education. Psychological Science, 29(4), 581-593. https://doi.org/10.1177/0956797617741719

Stoet, G., \& Geary, D. C. (2020). Sex-specific academic ability and attitude patterns in students across developed countries. Intelligence, 81, 101453.

https://doi.org/10.1016/j.intell.2020.101453

Strand, S., Deary, I. J., \& Smith, P. (2006). Sex differences in Cognitive Abilities Test scores: A UK national picture. British Journal of Educational Psychology, 76(3), 463-480. https://doi.org/10.1348/000709905X50906

Strand-Cary, M., \& Klahr, D. (2008). Developing elementary science skills: Instructional effectiveness and path independence. Cognitive Development, 23(4), 488-511. https://doi.org/10.1016/j.cogdev.2008.09.005 
Su, R., Rounds, J., \& Armstrong, P. I. (2009). Men and things, women and people: A meta-analysis of sex differences in interests. Psychological Bulletin, 135(6), 859-884. https://doi.org/10.1037/a0017364

Terman, L. M., \& Miles, C. C. (1936). Sex and personality: Studies in masculinity and feminity. The maple press company.

Terracciano, A., Abdel-Khalek, A. M., Ádám, N., Adamovová, L., Ahn, C. -k, Ahn, H. -n, Alansari, B. M., Alcalay, L., Allik, J., Angleitner, A., Avia, M. D., Ayearst, L. E., Barbaranelli, C., Beer, A., Borg-Cunen, M. A., Bratko, D., Brunner-Sciarra, M., Budzinski, L., Camart, N., ... McCrae, R. R. (2005). National character does not reflect mean personality trait levels in 49 cultures. Science, 310(5745), 96-100. https://doi.org/10.1126/science.1117199

Thuneberg, H., Hautamäki, J., \& Hotulainen, R. (2015). Scientific reasoning, school achievement and gender: A multilevel study of between and within school effects in Finland. Scandinavian Journal of Educational Research, 59(3), 337-356. https://doi.org/10.1080/00313831.2014.904426

Twenge, J. M. (1999). Mapping Gender. Psychology of Women Quarterly, 23(3), 485-502. https://doi.org/10.1111/j.1471-6402.1999.tb00377.x

Viechtbauer, W. (2010). Conducting meta-analyses in R with the metafor package. Journal of Statistical Software, 36(3), 1-48. https://doi.org/10.18637/jss.v036.i03

Vainikainen, M. P., \& Hautamäki, J. (2018). Selittääkö yrittäminen oppilaiden osaamisessa havaittuja ryhmäeroja? Itsearvioitu yrittäminen, investoitu työaika ja osaamiserot lokitietoanalyysin valossa. [Are group differences in perfomance explained by effort? Selfreported effort, time investment and performance differences in the light of log data analysis]. Psykologia, 53(2-3), 152-165. 
Voyer, D., Saint Aubin, J., Altman, K., \& Gallant, G. (2021). Sex differences in verbal working memory: A systematic review and meta-analysis. Psychological Bulletin, 147(4), 352-398. https://doi.org/10.1037/bul0000320

Wang, M. T., \& Degol, J. L. (2017). Gender gap in science, technology, engineering, and mathematics (STEM): Current knowledge, implications for practice, policy, and future directions. Educational Psychology Review, 29(1), 119-140. https://doi.org/10.1007/s10648-015-9355-x

Wechsler, D. (1981). WAIS-R manual: Wechsler adult intelligence scale-revised. Brace Jovanovich for Psychological Corp.

Wigfield, A., \& Eccles, J. S. (2000). Expectancy-Value Theory of achievement motivation. Contemporary Educational Psychology, 25(1), 68-81. https://doi.org/10.1006/ceps.1999.1015

Wilson, J. T. L., Scott, J. H., \& Power, K. G. (1987). Developmental differences in the span of visual memory for pattern. British Journal of Developmental Psychology, 5(3), 249-255. https://doi.org/10.1111/j.2044-835X.1987.tb01060.x

Wood, W., \& Eagly, A. H. (2015). Two Traditions of Research on Gender Identity. Sex Roles, 73(11), 461-473. https://doi.org/10.1007/s11199-015-0480-2

Yarkoni, T., \& Westfall, J. (2017). Choosing prediction over explanation in psychology: Lessons from machine learning. Perspectives on Psychological Science, 12(6), 1100-1122. https://doi.org/10.1177/1745691617693393

Young, R., \& Sweeting, H. (2004). Adolescent bullying, relationships, psychological well-being, and gender-atypical behavior: A gender diagnosticity approach. Sex Roles, 50(7), 525-537. https://doi.org/10.1023/B:SERS.0000023072.53886.86 
Table 1

Sex Differences in Femininity-Masculinity

\begin{tabular}{|c|c|c|c|c|c|c|c|c|}
\hline \multirow[b]{2}{*}{ Variable } & \multicolumn{2}{|c|}{ Girls } & \multicolumn{2}{|c|}{ Boys } & \multicolumn{3}{|c|}{$\begin{array}{c}\text { Standardized mean } \\
\text { difference }\end{array}$} & \multirow[b]{2}{*}{ OVL } \\
\hline & Mean & SD & Mean & SD & $D$ & $S D$ & $95 \% \mathrm{CI}$ & \\
\hline \multicolumn{9}{|l|}{ Personality } \\
\hline Factors & -0.51 & 0.87 & 0.25 & 0.91 & $0.86^{\mathrm{a}}$ & 0.04 & {$[0.78,0.94]$} & 66.85 \\
\hline Facets & -0.58 & 0.95 & 0.32 & 0.95 & 0.95 & 0.04 & {$[0.87,1.03]$} & 63.50 \\
\hline Personal Values & -0.38 & 0.69 & 0.17 & 0.78 & $0.75^{\mathrm{b}}$ & 0.04 & {$[0.68,0.83]$} & 70.74 \\
\hline \multicolumn{9}{|l|}{ Cognitive abilities } \\
\hline General & -0.02 & 0.14 & 0.00 & 0.14 & 0.15 & 0.03 & {$[0.08,0.22]$} & 93.84 \\
\hline Tests & -0.19 & 0.58 & 0.16 & 0.61 & $0.60^{c}$ & 0.03 & {$[0.54,0.67]$} & 76.56 \\
\hline \multicolumn{9}{|l|}{ Academic achievement } \\
\hline GPA & -0.17 & 0.54 & 0.15 & 0.56 & $0.57^{\mathrm{c}}$ & 0.03 & {$[0.51,0.63]$} & 77.46 \\
\hline Subjects & -1.04 & 1.39 & 1.09 & 1.50 & 1.48 & 0.04 & {$[1.40,1.55]$} & 46.07 \\
\hline Optional subjects & -0.25 & 0.66 & 0.24 & 0.69 & $0.72^{\mathrm{b}}$ & 0.04 & {$[0.65,0.79]$} & 71.79 \\
\hline \multicolumn{9}{|l|}{$\begin{array}{l}\text { Secondary school } \\
\text { application }\end{array}$} \\
\hline Academic/vocational & -0.05 & 0.21 & 0.01 & 0.24 & 0.24 & 0.03 & {$[0.18,0.30]$} & 90.38 \\
\hline Field & -0.38 & 0.93 & 0.41 & 1.12 & $0.77^{\mathrm{ab}}$ & 0.03 & {$[0.70,0.83]$} & 70.01 \\
\hline
\end{tabular}

Note: Femininity-Masculinity (FM) operationalized from probability of being a boy $\mathrm{P}(\mathrm{Boy}): \mathrm{FM}=\log (-\mathrm{P} /(\mathrm{P}-1))$. All numbers calculated across 1000 permutations (splits to training and testing sets) from the original data. $\mathrm{CI}=$ confidence interval based on percentile values, $2.5 \%$ and $97.5 \%$, across the permutations. Superscript indicates $D$ estimates for which pairwise between-domain comparison was non-significant, $\mathrm{p} \geq .05$. OVL $=$ overlapping coefficient, the proportion of distribution that is shared with the other sex, calculated from $2 \Phi(-D / 2)$. For other interpretations of standardized effect size, see https://rpsychologist.com/cohend/ (Magnusson, 2021). 
Table 2

Variance Ratio in Femininity-Masculinity, Predictive Accuracy of Femininity-

Masculinity, and Variance Explained by Femininity-Masculinity

\begin{tabular}{|c|c|c|c|c|c|c|c|c|c|}
\hline \multirow[b]{2}{*}{ Variable } & \multicolumn{3}{|c|}{ Variance Ratio } & \multicolumn{3}{|c|}{ Accuracy (\%) } & \multicolumn{3}{|c|}{$\mathrm{R}^{2}(\%)$} \\
\hline & $\mathrm{M}$ & $\mathrm{SD}$ & $\mathrm{CI}$ & $\mathrm{M}$ & $\mathrm{SD}$ & $\mathrm{CI}$ & $\mathrm{M}$ & $\mathrm{SD}$ & $\mathrm{CI}$ \\
\hline Personality & & & & & & & & & \\
\hline Factors & 1.09 & 0.08 & {$[0.94,1.25]$} & 68.0 & 1.0 & {$[66.1,69.9]$} & 11.6 & 1.1 & {$[9.7,13.8]$} \\
\hline Facets & 0.99 & 0.07 & {$[0.86,1.15]$} & 69.4 & 1.0 & {$[67.6,71.3]$} & 14.0 & 1.1 & {$[11.9,16.3]$} \\
\hline Values & 1.30 & 0.08 & {$[1.15,1.47]$} & 65.4 & 1.0 & {$[63.5,67.4]$} & 9.1 & 0.9 & {$[7.5,10.9]$} \\
\hline
\end{tabular}

Cognitive

abilities

$\begin{array}{rrrrrrrrrr}\text { General } & 1.02 & 0.04 & {[0.94,1.10]} & 52.4 & 0.9 & {[50.6,54.3]} & 0.4 & 0.2 & {[0.1,0.8]} \\ \text { Tasks } & 1.12 & 0.06 & {[1.01,1.23]} & 62.4 & 0.9 & {[60.8,64.1]} & 5.9 & 0.7 & {[4.8,7.4]}\end{array}$

Academic

achievement

$\begin{array}{llllllllll}\text { GPA } & 1.06 & 0.04 & {[0.98,1.14]} & 61.5 & 0.8 & {[60.0,63.2]} & 5.4 & 0.6 & {[4.4,6.6}\end{array}$

$\begin{array}{lllllllllll}\text { Subjects } & 1.17 & 0.06 & {[1.06,1.28]} & 77.5 & 0.7 & {[76.1,78.8]} & 30.0 & 1.3 & {[27.5,32.5]}\end{array}$

$\begin{array}{llllllllll}\begin{array}{l}\text { Optional } \\ \text { subjects }\end{array} & 1.07 & 0.04 & {[0.98,1.15]} & 65.0 & 1.0 & {[63.0,66.7]} & 8.5 & 0.8 & {[7.0,10.0]}\end{array}$

Secondary

school

application

$\begin{array}{cccccccccc}\text { Academic/ } & 1.29 & 0.04 & {[1.20,1.37]} & 55.6 & 0.8 & {[54.0,57.1]} & 1.0 & 0.3 & {[0.5,1.6}\end{array}$

$\begin{array}{llllllllll}\text { Field } & 1.53 & 0.40 & {[0.73,2.41]} & 62.1 & 1.0 & {[59.5,63.8]} & 9.6 & 0.8 & {[7.9,11.0]}\end{array}$

Note: All numbers calculated across 1000 permutations (splits to training and testing sets) from the original data. Accuracy is the ability to correctly assign sex in the testing data. $\mathrm{R}^{2}$ is McFadden's Pseudo- $\mathrm{R}^{2}$ from logistic regressions where predicted values based on training data coefficients were used to predict sex in the testing data. $\mathrm{CI}=$ confidence interval based on percentile values, $2.5 \%$ and $97.5 \%$, across the permutations. 
Table 3

Mean Gender Typicality of Girls and Boys

Gender typicality

(proportion of girls / boys)

\begin{tabular}{lrccccc}
\cline { 3 - 6 } Variable & $\begin{array}{c}\text { Very } \\
\text { atypical }\end{array}$ & $\begin{array}{c}\text { Somewhat } \\
\text { atypical }\end{array}$ & Indifferent & $\begin{array}{c}\text { Somewhat } \\
\text { typical }\end{array}$ & $\begin{array}{c}\text { Very } \\
\text { typical }\end{array}$ \\
\hline Personality & & & & & & \\
& Factors & $.01 / .03^{*}$ & $.13 / .18$ & $.31 / .36$ & $.39 / .34$ & $.15 / .09^{*}$ \\
Facets & $.03 / .03$ & $.12 / .18^{*}$ & $.27 / .33^{*}$ & $.39 / .35$ & $.20 / .11^{* *}$ \\
Personal Values & $.01 / .02$ & $.12 / .20^{*}$ & $.36 / .41$ & $.46 / .31^{* *}$ & $.06 / .06$
\end{tabular}

Cognitive abilities

$\begin{array}{rlllll}\text { General } & .00 / .00 & .00 / .00 & .99 / .99 & .00 / .00 & .00 / .00 \\ \text { Tasks } & .01 / .01 & .13 / .16 & .51 / .49 & .32 / .32 & .02 / .02\end{array}$

Academic

achievement

$\begin{array}{rrrrrr}\text { GPA } & .00 / .00 & .15 / .16 & .48 / .52 & .36 / .30 & .00 / .02^{*} \\ \text { Subjects } & .05 / .05 & .10 / .11 & .16 / .16 & .28 / .26 & .41 / .42 \\ & & & & & \\ \text { ects } & .00 / .01 & .18 / .19 & .36 / .34 & .43 / .46 & .03 / .00\end{array}$

Secondary school

application

$\begin{array}{llllll}\text { Academic/ vocational } & .00 / .00 & .04 / .00 & .96 / .95 & .00 / .05 & .00 / .00\end{array}$

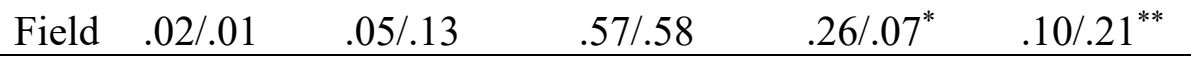

Note: Gender typicality was categorized from the basis of predicted probabilities of being a boy. Very typical corresponded to probabilities between .8 and 1.0 for boys and .0 and .20 for girls, somewhat typical to $.6-.8$ for boys and .2-.4 for girls, indifferent .4.6 for both, somewhat atypical .2-.4 for boys and .6-.8 for girls, and very atypical .0-.2 for boys and .8-1.0 for girls. Numbers are mean proportions of girls and boys belonging to each category across the permutations.

* Difference in proportions of girls and boys in the category to the direction presented in the table was observed in at least $95 \%$ of the permutations

** Difference in proportions of girls and boys in the category to the direction presented in the table was observed in at least $99 \%$ of the permutations 
Table 4

Partial Correlations between FM Scores

\begin{tabular}{|c|c|c|c|c|c|}
\hline & \multicolumn{2}{|c|}{ Partial } & \multicolumn{2}{|c|}{ Unique partial } \\
\hline & & $r^{\prime}$ & $\mathrm{CI}$ & $r_{u}^{\prime}$ & $\mathrm{CI}$ \\
\hline Personality & Values & .34 & {$[.29, .39]$} & .33 & {$[.28, .38]$} \\
\hline Personality & Cognitive tests & .06 & {$[.01, .10]$} & .01 & {$[-.03, .05]$} \\
\hline Personality & Grades & .12 & {$[.07, .16]$} & .08 & {$[.04, .13]$} \\
\hline Personality & Optional subjects & .06 & {$[.01, .11]$} & .04 & {$[-.01, .09]$} \\
\hline Personality & Application & .03 & {$[-.02, .07]$} & .01 & {$[-.04, .05]$} \\
\hline Values & Cognitive tests & .10 & {$[.06, .15]$} & .08 & {$[.04, .13]$} \\
\hline Values & Grades & .10 & {$[.06, .15]$} & .06 & {$[.02, .10]$} \\
\hline Values & Optional subjects & .05 & {$[.00, .09]$} & .02 & {$[-.02, .06]$} \\
\hline Values & Application & .03 & {$[-.01, .07]$} & .01 & {$[-.03, .05]$} \\
\hline Cognitive tests & Grades & .10 & {$[.06, .15]$} & .08 & {$[.04, .12]$} \\
\hline Cognitive tests & Optional subjects & .07 & {$[.03, .11]$} & .06 & {$[.02, .09]$} \\
\hline Cognitive tests & Application & .04 & {$[-.00, .07]$} & .02 & {$[-.02, .06]$} \\
\hline Grades & Optional subjects & .09 & {$[.05, .13]$} & .07 & {$[.03, .11]$} \\
\hline Grades & Application & .09 & {$[.05, .13]$} & .08 & {$[.04, .12]$} \\
\hline Optional subjects & Application & .06 & {$[.02, .10]$} & .05 & {$[.01, .09]$} \\
\hline
\end{tabular}

Note: Partial $=$ Correlation from which sex was partialed out. Unique partial $=$ Correlation from which sex and other FM scores were partialed out. CI = confidence interval based on percentile values, $2.5 \%$ and $97.5 \%$, across the permutations. 
Table 5

Within-Sex FM score Correlations

\begin{tabular}{|c|c|c|c|c|c|c|}
\hline & \multicolumn{2}{|c|}{ Girls } & \multicolumn{2}{|r|}{ Boys } & \multirow[b]{2}{*}{$p$} \\
\hline & & $r$ & $\mathrm{CI}$ & $r$ & $\mathrm{CI}$ & \\
\hline Personality & Values & .37 & {$[.30, .42]$} & .32 & {$[.24, .39]$} & .273 \\
\hline Personality & Cognitive tests & .05 & {$[-.01, .11]$} & .06 & {$[-.01, .12]$} & .837 \\
\hline Personality & Grades & .10 & {$[.05, .16]$} & .14 & {$[.08, .21]$} & .321 \\
\hline Personality & Optional subjects & .05 & {$[-.01, .11]$} & .09 & {$[.02, .15]$} & .402 \\
\hline Personality & Application & .00 & {$[-.07, .07]$} & .06 & {$[.01, .12]$} & .219 \\
\hline Values & Cognitive tests & .13 & {$[.07, .20]$} & .07 & {$[.01, .13]$} & .128 \\
\hline Values & Grades & .05 & {$[-.00, .11]$} & .16 & {$[.10, .22]$} & .006 \\
\hline Values & Optional subjects & .07 & {$[.01, .12]$} & .05 & {$[-.02, .11]$} & .583 \\
\hline Values & Application & .02 & {$[-.03, .08]$} & .04 & {$[-.01, .10]$} & .632 \\
\hline Cognitive tests & Grades & .12 & {$[.06, .17]$} & .09 & {$[.04, .15]$} & .493 \\
\hline Cognitive tests & Optional subjects & .04 & {$[-.01, .09]$} & .10 & {$[.05, .15]$} & .073 \\
\hline Cognitive tests & Application & .01 & {$[-.04, .07]$} & .06 & {$[-.00, .11]$} & .312 \\
\hline Grades & Optional subjects & .07 & {$[.03, .12]$} & .10 & {$[.05, .15]$} & .524 \\
\hline Grades & Application & .03 & {$[-.03, .08]$} & .14 & {$[.09, .19]$} & .007 \\
\hline Optional subjects & Application & .10 & {$[.05, .15]$} & .02 & {$[-.03, .08]$} & .034 \\
\hline
\end{tabular}

Note: $r=$ mean within-sex correlation across permutations. $\mathrm{CI}=$ confidence interval based on percentile values, $2.5 \%$ and $97.5 \%$, across the permutations. $p=$ significance test for the difference between girls' and boys' within-sex correlations. 
Table 6

Node Strengths in Partial and Within-Sex FM-Score Correlation Networks

\begin{tabular}{|c|c|c|c|c|c|c|c|}
\hline & & & \multicolumn{5}{|c|}{ Within-Sex } \\
\hline & \multicolumn{2}{|c|}{ Partial } & \multicolumn{2}{|c|}{ Girls } & \multicolumn{2}{|r|}{ Boys } & \multirow[b]{2}{*}{$p$} \\
\hline & $\Sigma\left|r^{\prime}\right|$ & $\mathrm{CI}$ & $\Sigma|r|$ & $\mathrm{CI}$ & $\sum|r|$ & $\mathrm{CI}$ & \\
\hline Personality & $0.60^{\mathrm{ab}}$ & {$[0.49,0.73]$} & $0.60^{\mathrm{a}}$ & {$[0.48,0.74]$} & $0.66^{\mathrm{a}}$ & {$[0.50,0.83]$} & .524 \\
\hline Values & $0.63^{\mathrm{a}}$ & {$[0.51,0.74]$} & $0.65^{\mathrm{a}}$ & {$[0.51,0.79]$} & $0.64^{\mathrm{a}}$ & {$[0.48,0.80]$} & .931 \\
\hline Cognitive tests & $0.37^{\mathrm{c}}$ & {$[0.25,0.49]$} & $0.37^{b c}$ & {$[0.23,0.51]$} & $0.38^{\mathrm{b}}$ & {$[0.23,0.54]$} & .881 \\
\hline Grades & $0.50^{\mathrm{b}}$ & {$[0.39,0.61]$} & $0.38^{\mathrm{b}}$ & {$[0.25,0.52]$} & $0.63^{\mathrm{a}}$ & {$[0.48,0.78]$} & .010 \\
\hline Optional subjects & $0.32^{\mathrm{c}}$ & {$[0.21,0.44]$} & $0.33^{b c}$ & {$[0.21,0.47]$} & $0.36^{\mathrm{b}}$ & {$[0.23,0.51]$} & .757 \\
\hline Application & $0.24^{\mathrm{c}}$ & {$[0.15,0.36]$} & $0.22^{\mathrm{c}}$ & {$[0.12,0.34]$} & $0.33^{\mathrm{b}}$ & {$[0.20,0.48]$} & .199 \\
\hline
\end{tabular}

Note: $\mathrm{CI}=$ confidence interval based on percentile values, $2.5 \%$ and $97.5 \%$, across the permutations. Shared superscripts between estimates indicate which estimates were not significantly different for each column. $p=$ significance test for the difference between girls' and boys' estimates. 
A. Partial correlations

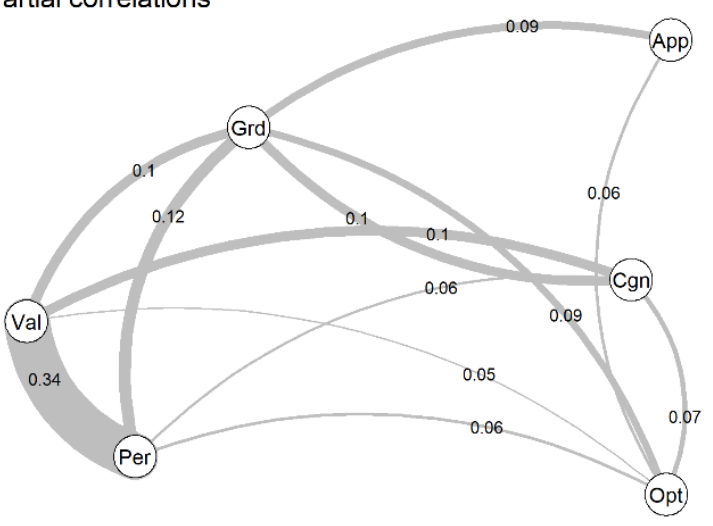

C. Correlations: Boys

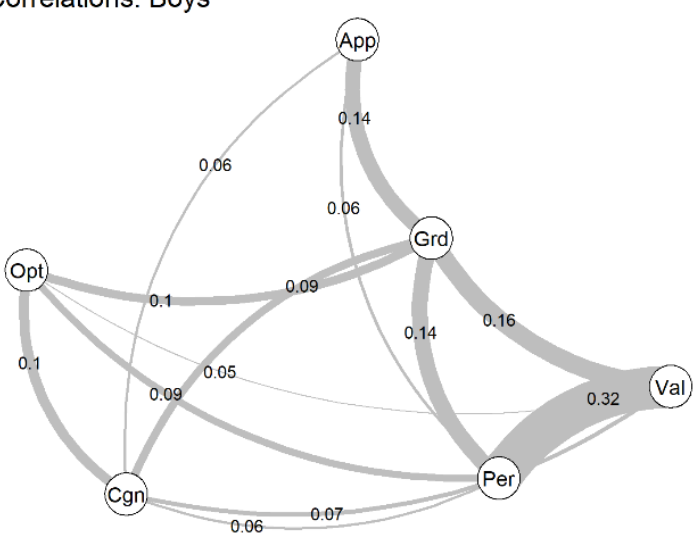

E. Correlations: Girls

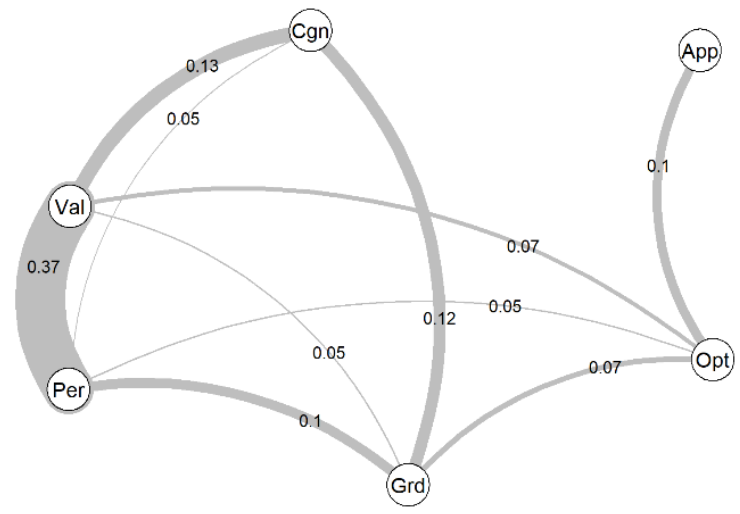

B. Unique partial correlations

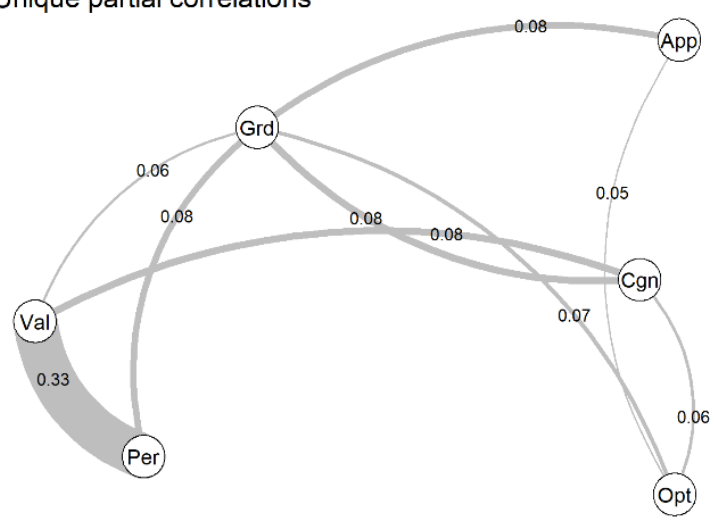

D. Unique correlations: Boys

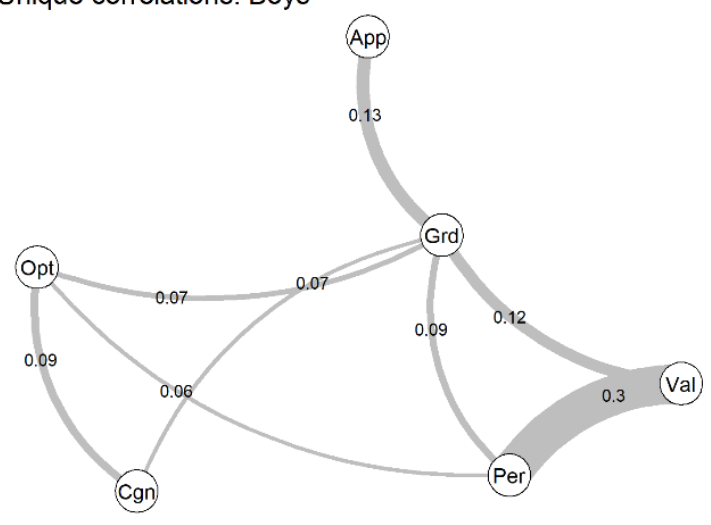

F. Unique correlations: Girls

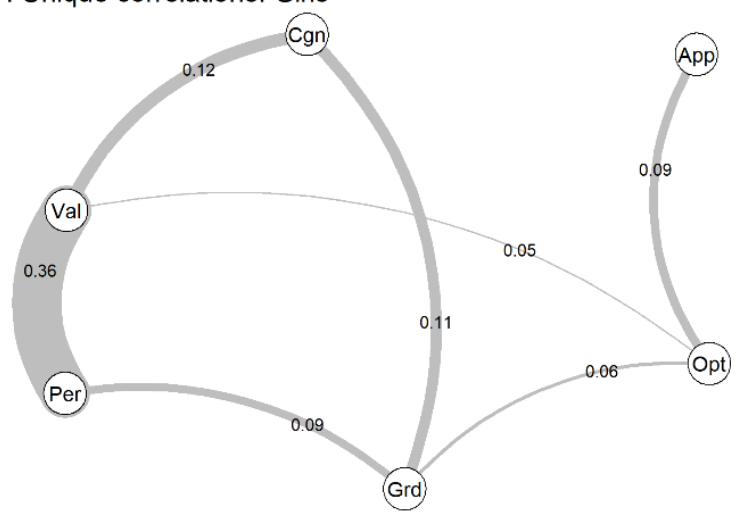

Figure 1

Association Networks between FM-scores for All Participants (panels A and B), Boys (panels C and $D)$, and Girls (panels $E$ and F).

Note. Abbreviations for FM-scores: App $=$ Educational Track Applied for; $\mathrm{Cgn}=$ Cognitive Abilities; Grd = Academic Grades; Opt = Optional Subjects Selected; Per = Personality; Val = Values. Associations smaller than .05 were not drawn. Layouts were averaged within each row. 


\section{SUPPLEMENTARY MATERIALS}

\section{Comparison of $D$ Estimators in Three Simulated Scenarios}

To assess the adequacy of logistic regression in the estimation of $D$, we compared the result it produced with those given by alternative methods in three different simulated data scenarios. The first data was univariate and $d$ in the population was 0.3 . The second data was multivariate with ten covarying dimensions (the bivariate correlations between dimensions ranged from $r=-0.5$ to $r=$ $0.5)$. The sex difference on these dimensions ranged from $d=-0.5$ to $d=0.5$, resulting in $D=1.44$ in the population. The third data was similar to the second, except that there were no sex differences (and thus $D$ was 0 ). In the first data, result obtained with Cohen's $d$ were compared with those given by logistic regression. In the second and third data, Mahalanobis' $D$ and linear discriminant analysis were compared with logistic regression. We also included a penalized variant of the logistic regression (elastic net) in the comparison. This was done to assess whether penalizing by shrinking the coefficients towards zero in order to avoid overfitting would affect estimates (a known problem of Mahalanobis' $D$ in smaller samples; Del Giudice, 2013). The three data sets were generated with 500 females and 500 males in each, and this was repeated 1000 times. The performance of each estimator was recorded across these trials. See supplementary materials (https://osf.io/gpcyh/) for R script and output for each scenario.

In the first simulated data scenario, the standardized mean difference (Cohen's $d$ ) computed directly from the data was identical with the estimates computed using the predicted values produced by logistic regression (the means across the 1000 trials were identical to the seventh decimal: 0.3013595). The accuracy of estimation was also identical (RMSE for both $0.06505702)$.

In the second scenario, with ten correlated variables and population $D=1.44$, the mean estimates of $D$ and RMSE were 1.45 and $0.071,1.46$ and $0.073,1.46$ and $0.073,1.46$ and 0.072 , for 
Mahalanobis' $D$, discriminant analysis, logistic regression, and elastic net, respectively. All values were thus good and very similar.

In the third scenario, with ten correlated variables but no sex differences, the mean estimate of $D$ was 0.20 for Mahalanobis' $D$, discriminant analysis, and logistic regression. By contrast, it was only 0.06 for elastic net, making it superior to the other estimators. In addition, in 658 of the 1000 trials, elastic net correctly penalized all ten coefficient weights to zero, resulting in $D=0$. Because of this, elastic net also performed better in terms of accuracy (RMSE for elastic net was 0.11 and 0.20 for the other three estimators).

In conclusion, logistic regression accurately estimated sex differences in both univariate and multivariate scenarios. That the performance of logistic regression was similar to that of Mahalanobis' $D$ and discriminant analysis suggests that it can be used also with data that satisfies the rather stringent assumptions of the latter, besides being the obvious choice when these assumptions are not satisfied (e.g., non-normal or categorical data). Furthermore, the penalized version of logistic regression should be preferred, as it performed similarly to other estimates when an actual effect was present but outperformed them in the absence of an effect. 
Table S1

Correlations Between Cognitive Tests

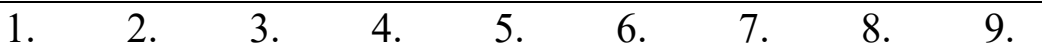

1. Invented math concepts $\quad .79$

2. Hidden arithmetic operators $\quad .41 \quad .80$

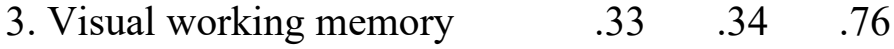

$\begin{array}{lllll}\text { 4. Mental arithmetic } & .29 & .27 & .29 & .83\end{array}$

$\begin{array}{lllllll}\text { 5. Analogical reasoning } & & .35 & .41 & .33 & .20 & .75\end{array}$

$\begin{array}{llllllll}\text { 6. Reading comprehension } & & 33 & .48 & .23 & .17 & .34 & .65\end{array}$

(multiple choice)

$\begin{array}{llllll}.33 & .48 & .23 & .17 & .34 & .65\end{array}$

7. Verbal proportional

reasoning

$\begin{array}{lllllll}.44 & .35 & .29 & .27 & .34 & .35 & .67\end{array}$

8. Reading comprehension

(macroprocessing)

$\begin{array}{llllllll}.24 & .28 & .18 & .13 & .32 & .25 & .29 & .69\end{array}$

9. Scientific reasoning

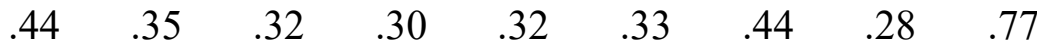

Note. Numbers on diagonal are item-response theory based reliabilities for dichotomous items $\pi_{(2)}$, see Cheng et al. 2012. All correlations statistically significant, $p<.001$. Pairwise sample sizes range from 2734 to 3621 . 
Table S2

Coefficient Weight Distributions across Training Set Permutations for Personality Trait Factors

\begin{tabular}{lcccccc}
\hline & $\mathrm{B}$ & $\mathrm{SE}$ & $2.5 \%$ & $97.5 \%$ & OR & $\begin{array}{c}\text { Non- } \\
\text { zero }\end{array}$ \\
\hline Intercept & 9.72 & 0.67 & 8.45 & 11.03 & & 1000 \\
$\mathrm{~N}$ & -0.81 & 0.07 & -0.94 & -0.67 & 0.45 & 1000 \\
$\mathrm{E}$ & -0.36 & 0.06 & -0.48 & -0.24 & 0.70 & 1000 \\
$\mathrm{O}$ & -0.55 & 0.06 & -0.67 & -0.44 & 0.58 & 1000 \\
$\mathrm{~A}$ & -0.45 & 0.06 & -0.56 & -0.35 & 0.64 & 1000 \\
$\mathrm{C}$ & -0.27 & 0.06 & -0.38 & -0.15 & 0.77 & 1000 \\
\hline
\end{tabular}

Note: $\mathrm{N}=$ Neuroticism. $\mathrm{E}=$ Extraversion. $\mathrm{O}=$ Openness to Experience. $\mathrm{A}=$ Agreeableness. $\mathrm{C}=$ Conscientiousness. $\mathrm{OR}=$ Odds-ratio. Non-zero $=$ Number of permutations in which the coefficient was not penalized to zero. 
Table S3

Coefficient Weight Distributions across Training Set Permutations for Personality Facets

\begin{tabular}{|c|c|c|c|c|c|c|}
\hline & B & SE & $2.5 \%$ & $97.5 \%$ & OR & $\begin{array}{l}\text { Non- } \\
\text { zero }\end{array}$ \\
\hline Intercept & 7.44 & 0.82 & 5.86 & 9.01 & & 1000 \\
\hline N1 & -0.18 & 0.04 & -0.25 & -0.10 & 0.84 & 1000 \\
\hline E1 & -0.02 & 0.03 & -0.08 & 0.00 & 0.98 & 606 \\
\hline $\mathrm{O} 1$ & 0.01 & 0.02 & -0.01 & 0.07 & 1.01 & 604 \\
\hline A1 & 0.02 & 0.02 & -0.01 & 0.07 & 1.02 & 622 \\
\hline $\mathrm{C} 1$ & -0.04 & 0.04 & -0.12 & 0.00 & 0.96 & 756 \\
\hline $\mathrm{N} 2$ & -0.06 & 0.04 & -0.14 & 0.00 & 0.94 & 928 \\
\hline E2 & -0.03 & 0.03 & -0.09 & 0.00 & 0.97 & 772 \\
\hline $\mathrm{O} 2$ & -0.12 & 0.02 & -0.17 & -0.07 & 0.89 & 1000 \\
\hline $\mathrm{A} 2$ & -0.02 & 0.03 & -0.09 & 0.00 & 0.98 & 677 \\
\hline $\mathrm{C} 2$ & -0.04 & 0.03 & -0.10 & 0.00 & 0.96 & 841 \\
\hline N3 & -0.13 & 0.04 & -0.20 & -0.05 & 0.88 & 1000 \\
\hline E3 & 0.05 & 0.04 & 0.00 & 0.13 & 1.06 & 905 \\
\hline $\mathrm{O} 3$ & -0.20 & 0.03 & -0.26 & -0.13 & 0.82 & 1000 \\
\hline $\mathrm{A} 3$ & -0.01 & 0.02 & -0.06 & 0.04 & 0.99 & 377 \\
\hline $\mathrm{C} 3$ & -0.20 & 0.04 & -0.29 & -0.12 & 0.82 & 1000 \\
\hline N4 & -0.05 & 0.04 & -0.14 & 0.00 & 0.95 & 859 \\
\hline E4 & -0.05 & 0.04 & -0.13 & 0.00 & 0.95 & 893 \\
\hline $\mathrm{O} 4$ & 0.00 & 0.02 & -0.04 & 0.04 & 1.00 & 495 \\
\hline A4 & -0.01 & 0.02 & -0.05 & 0.02 & 0.99 & 518 \\
\hline $\mathrm{C} 4$ & -0.02 & 0.02 & -0.08 & 0.01 & 0.98 & 591 \\
\hline N5 & -0.08 & 0.03 & -0.14 & -0.01 & 0.93 & 988 \\
\hline E5 & -0.05 & 0.03 & -0.13 & 0.00 & 0.95 & 919 \\
\hline O5 & 0.00 & 0.02 & -0.05 & 0.03 & 1.00 & 422 \\
\hline A5 & -0.11 & 0.04 & -0.18 & -0.03 & 0.90 & 998 \\
\hline $\mathrm{C} 5$ & 0.03 & 0.03 & 0.00 & 0.10 & 1.03 & 753 \\
\hline N6 & -0.09 & 0.04 & -0.16 & -0.01 & 0.92 & 985 \\
\hline E6 & -0.19 & 0.04 & -0.27 & -0.12 & 0.82 & 1000 \\
\hline O6 & -0.20 & 0.03 & -0.26 & -0.14 & 0.82 & 1000 \\
\hline A6 & -0.05 & 0.04 & -0.13 & 0.00 & 0.95 & 896 \\
\hline C6 & -0.02 & 0.03 & -0.09 & 0.00 & 0.98 & 685 \\
\hline
\end{tabular}

Note: $\mathrm{N}=$ Neuroticism. $\mathrm{E}=$ Extraversion. $\mathrm{O}=$ Openness to

Experience. $\mathrm{A}=$ Agreeableness. $\mathrm{C}=$ Conscientiousness. $\mathrm{OR}=$ Oddsratio. Non-zero $=$ Number of permutations in which the coefficient was not penalized to zero. 
Table S4

Coefficient Weight Distributions across Training Set Permutations for Personal Values

\begin{tabular}{lcccccc}
\hline & $\mathrm{B}$ & $\mathrm{SE}$ & $2.5 \%$ & $97.5 \%$ & $\mathrm{OR}$ & $\begin{array}{c}\text { Non- } \\
\text { zero }\end{array}$ \\
Intercept & 1.06 & 0.25 & 0.56 & 1.54 & & 1000 \\
PO & 0.16 & 0.02 & 0.12 & 0.20 & 1.18 & 1000 \\
$\mathrm{AC}$ & 0.01 & 0.02 & -0.02 & 0.06 & 1.01 & 663 \\
$\mathrm{HE}$ & -0.01 & 0.02 & -0.06 & 0.04 & 0.99 & 575 \\
$\mathrm{ST}$ & -0.04 & 0.02 & -0.09 & 0.00 & 0.96 & 930 \\
$\mathrm{SD}$ & -0.01 & 0.02 & -0.06 & 0.02 & 0.99 & 663 \\
$\mathrm{UN}$ & -0.10 & 0.02 & -0.15 & -0.05 & 0.91 & 1000 \\
$\mathrm{BE}$ & -0.28 & 0.03 & -0.35 & -0.22 & 0.75 & 1000 \\
TR & 0.08 & 0.02 & 0.04 & 0.13 & 1.09 & 1000 \\
CO & 0.04 & 0.03 & 0.00 & 0.10 & 1.05 & 891 \\
SE & -0.04 & 0.03 & -0.10 & 0.00 & 0.96 & 826 \\
\hline
\end{tabular}

Note: $\mathrm{PO}=$ Power. $\mathrm{AC}=$ Achievement. $\mathrm{HE}=$ Hedonism. $\mathrm{ST}=$

Stimulation. $\mathrm{SD}=$ Self-direction. $\mathrm{UN}=$ Universalism. $\mathrm{BE}=$

Benevolence. $\mathrm{TR}=$ Tradition $. \mathrm{CO}=$ Conservation. $\mathrm{SE}=$ Security. $\mathrm{OR}$

$=$ Odds-ratio. Non-zero $=$ Number of permutations in which the coefficient was not penalized to zero. 


\section{Table S5}

Coefficient Weight Distributions across Training Set Permutations for General Cognitive Ability, $g$

\begin{tabular}{lcccccc}
\hline & $\mathrm{B}$ & $\mathrm{SE}$ & $2.5 \%$ & $97.5 \%$ & $\mathrm{OR}$ & $\begin{array}{r}\text { Non- } \\
\text { zero }\end{array}$ \\
\hline Intercept & -0.01 & 0.03 & -0.08 & 0.05 & & 1000 \\
$g$ & -0.15 & 0.04 & -0.23 & -0.08 & 0.86 & 997 \\
\hline Note: OR = Odds-ratio. Non-zero & $=$ Number of permutations in \\
which the coefficient was not penalized to zero.
\end{tabular}


Table S6

Coefficient Weight Distributions across Training Set Permutations for Cognitive Tasks

\begin{tabular}{lcccccc}
\hline & $\mathrm{B}$ & $\mathrm{SE}$ & $2.5 \%$ & $97.5 \%$ & OR & Non-zero \\
\hline Intercept & -0.01 & 0.04 & -0.08 & 0.06 & & 1000 \\
Invented mathematical concepts & -0.01 & 0.02 & -0.04 & 0.02 & 0.99 & 709 \\
Hidden arithmetic operators & -0.06 & 0.03 & -0.12 & -0.01 & 0.94 & 993 \\
Visual working memory & 0.04 & 0.02 & 0.00 & 0.07 & 1.04 & 954 \\
Mental arithmetics & 0.25 & 0.02 & 0.21 & 0.29 & 1.28 & 1000 \\
Analogical reasoning & -0.05 & 0.02 & -0.09 & 0.00 & 0.95 & 974 \\
Reading comprehension: & -0.24 & 0.04 & -0.32 & -0.17 & 0.78 & 1000 \\
Multiple-choice & -0.08 & 0.02 & -0.13 & -0.04 & 0.92 & 1000 \\
Verbal proportional reasoning & -0.03 & 0.01 & -0.06 & -0.01 & 0.97 & 994 \\
Reading comprehension: & & & & & \\
Macroprocessing & 0.03 & 0.03 & -0.01 & 0.09 & 1.03 & 792 \\
Scientific reasoning & N & &
\end{tabular}

Note: $\mathrm{OR}=$ Odds-ratio. Non-zero $=$ Number of permutations in which the coefficient was not penalized to zero. 


\section{Table S7}

Coefficient Weight Distributions across Training Set Permutations for Grade Point Average, GPA

\begin{tabular}{lcccccc}
\hline & $\mathrm{B}$ & $\mathrm{SE}$ & $2.5 \%$ & $97.5 \%$ & $\mathrm{OR}$ & $\begin{array}{c}\text { Non- } \\
\text { zero }\end{array}$ \\
\hline Intercept & -0.04 & 0.03 & -0.11 & 0.02 & & 1000 \\
GPA & -0.68 & 0.04 & -0.76 & -0.60 & 0.51 & 1000 \\
\hline Note: OR & Odds-ratio & Non
\end{tabular}

Note: $\mathrm{OR}=$ Odds-ratio. Non-zero $=$ Number of permutations in which the coefficient was not penalized to zero. 
Table S8

Coefficient Weight Distributions across Training Set Permutations for Grades

\begin{tabular}{|c|c|c|c|c|c|c|}
\hline & B & SE & $2.5 \%$ & $97.5 \%$ & OR & $\begin{array}{l}\text { Non- } \\
\text { zero }\end{array}$ \\
\hline Intercept & -0.02 & 0.04 & -0.10 & 0.06 & & 1000 \\
\hline Native language & -0.76 & 0.07 & -0.91 & -0.62 & 0.47 & 1000 \\
\hline $\begin{array}{l}\text { First foreign } \\
\text { language }\end{array}$ & 0.22 & 0.05 & 0.12 & 0.30 & 1.24 & 1000 \\
\hline Biology & -0.21 & 0.08 & -0.36 & -0.06 & 0.81 & 996 \\
\hline Physics & 0.51 & 0.07 & 0.36 & 0.66 & 1.67 & 1000 \\
\hline Geography & 0.26 & 0.07 & 0.13 & 0.41 & 1.30 & 999 \\
\hline History & 0.60 & 0.06 & 0.49 & 0.72 & 1.83 & 1000 \\
\hline Chemistry & 0.09 & 0.07 & -0.01 & 0.22 & 1.09 & 911 \\
\hline $\begin{array}{l}\text { Home } \\
\text { economics }\end{array}$ & -0.83 & 0.07 & -0.97 & -0.69 & 0.44 & 1000 \\
\hline Handicraft & 0.07 & 0.06 & -0.02 & 0.19 & 1.08 & 927 \\
\hline Ethical studies & -0.33 & 0.06 & -0.45 & -0.22 & 0.72 & 1000 \\
\hline Visual arts & -1.04 & 0.07 & -1.17 & -0.91 & 0.35 & 1000 \\
\hline $\begin{array}{l}\text { Physical } \\
\text { training }\end{array}$ & 0.35 & 0.05 & 0.25 & 0.45 & 1.42 & 1000 \\
\hline Mathematics & 0.26 & 0.06 & 0.14 & 0.38 & 1.30 & 1000 \\
\hline Music & -0.24 & 0.05 & -0.35 & -0.14 & 0.79 & 1000 \\
\hline $\begin{array}{l}\text { Health } \\
\text { education }\end{array}$ & -0.62 & 0.07 & -0.77 & -0.48 & 0.54 & 1000 \\
\hline Social studies & 0.01 & 0.05 & -0.10 & 0.11 & 1.01 & 754 \\
\hline
\end{tabular}

Note: $\mathrm{OR}=$ Odds-ratio. Non-zero $=$ Number of permutations in which the coefficient was not penalized to zero. 
Table S9

Coefficient Weight Distributions across Training Set Permutations for Optional Subjects

\begin{tabular}{lcccccc}
\hline B & SE & $2.5 \%$ & $97.5 \%$ & OR & $\begin{array}{c}\text { Non- } \\
\text { zero }\end{array}$ \\
\hline Intercept & -0.10 & 0.10 & -0.30 & 0.09 & 0.91 & 1000 \\
Biology & -0.35 & 0.25 & -0.90 & 0.00 & 0.72 & 882 \\
History & 0.77 & 0.58 & 0.00 & 1.88 & 2.80 & 891 \\
Chemistry & -0.47 & 0.41 & -1.31 & 0.00 & 0.67 & 847 \\
Home economics & -0.17 & 0.08 & -0.33 & 0.00 & 0.85 & 973 \\
Handicraft & 0.33 & 0.07 & 0.18 & 0.47 & 1.39 & 1000 \\
Ethical studies & -0.74 & 0.08 & -0.91 & -0.60 & 0.48 & 1000 \\
Physical training & 0.96 & 0.08 & 0.82 & 1.13 & 2.63 & 1000 \\
Mathematics & 0.12 & 0.18 & -0.13 & 0.54 & 1.15 & 654 \\
Music & -0.49 & 0.09 & -0.66 & -0.32 & 0.61 & 1000 \\
Social studies & 0.44 & 0.58 & -0.15 & 1.45 & 3.12 & 768 \\
\hline
\end{tabular}

Note: $\mathrm{OR}=$ Odds-ratio. Non-zero $=$ Number of permutations in which the coefficient was not penalized to zero. 


\section{Table S10}

Coefficient Weight Distributions Across Training Set Permutations

For Secondary Education Application (Academic Vs. Vocational

Track)

\begin{tabular}{lcccccc}
\hline & $\mathrm{B}$ & $\mathrm{SE}$ & $2.5 \%$ & $97.5 \%$ & $\mathrm{OR}$ & $\begin{array}{c}\text { Non- } \\
\text { zero }\end{array}$ \\
\hline $\begin{array}{l}\text { Intercept } \\
\begin{array}{l}\text { Academic } \\
\text { track }\end{array}\end{array}$ & -0.16 & 0.04 & -0.23 & -0.08 & & 1000 \\
\hline
\end{tabular}

Note: OR $=$ Odds-ratio. Non-zero $=$ Number of permutations in which the coefficient was not penalized to zero. 
Table S11

Coefficient Weight Distributions across Training Set Permutations for

Secondary Education Application Branches (Reference Group in the

Categorical Predictor: Vocational Institute - Technical And Traffic)

\begin{tabular}{lcccccc}
\hline & $\mathrm{B}$ & $\mathrm{SE}$ & $2.5 \%$ & $97.5 \%$ & OR & $\begin{array}{c}\text { non- } \\
\text { zero }\end{array}$ \\
\hline Intercept & 2.03 & 0.20 & 1.68 & 2.46 & & 1000 \\
Voc Cult & -1.89 & 0.33 & -2.51 & -1.22 & 0.16 & 1000 \\
Voc Heal Care & -3.80 & 0.33 & -4.53 & -3.22 & 0.02 & 1000 \\
Voc Beau Care & -5.63 & 1.09 & -8.63 & -4.36 & 0.01 & 1000 \\
Voc Educ & -3.31 & 1.01 & -6.46 & -2.04 & 0.06 & 1000 \\
Voc Natu Reso & -5.43 & 1.50 & -8.31 & -3.52 & 0.01 & 1000 \\
Voc Secu & -1.12 & 0.55 & -2.06 & -0.01 & 0.45 & 992 \\
Voc Merc & -1.67 & 0.25 & -2.20 & -1.21 & 0.19 & 1000 \\
Voc Data & 1.29 & 0.74 & 0.35 & 3.47 & 5.80 & 1000 \\
Voc Trav Cate & -2.82 & 0.31 & -3.46 & -2.25 & 0.06 & 1000 \\
High school Lang & -2.60 & 0.24 & -3.12 & -2.15 & 0.08 & 1000 \\
High school Cult & -2.85 & 0.23 & -3.35 & -2.43 & 0.06 & 1000 \\
High school Spor & -1.71 & 0.24 & -2.20 & -1.24 & 0.19 & 1000 \\
High school Natu & -1.96 & 0.30 & -2.57 & -1.41 & 0.15 & 1000 \\
High school Soci & -1.42 & 0.34 & -2.11 & -0.79 & 0.26 & 1000 \\
High school Busi & -1.81 & 0.46 & -2.76 & -0.85 & 0.18 & 999 \\
High school Stei & -2.09 & 0.50 & -3.10 & -1.17 & 0.14 & 1000 \\
High school Gene & -2.11 & 0.21 & -2.54 & -1.73 & 0.12 & 1000 \\
\hline
\end{tabular}

Note: Abbreviations: Voc $=$ Vocational institute. $\mathrm{Cult}=$ Cultural. Heal Care $=$ Health care. Beau Care $=$ Beauty care. Educ $=$ Educational. Natu Reso $=$ Natural resources and environment. Secu $=$ Security. Merc $=$ Business [merkonomi]. Data $=$ Information technology [datanomi]. Trav Cate $=$ Travel, catering, and domestic economics. Lang $=$ Language emphasis. Spor $=$ Sports and exercise emphasis. $\mathrm{Natu}=$ Natural science emphasis. Soci $=$ Social science emphasis. Busi $=$ Business emphasis. Stei $=$ Steiner high school. Norm $=$ General high schools. OR $=$ Odds-ratio. Non-zero $=$ Number of permutations in which the coefficient was not penalized to zero. 
Table S12

Coefficient Weight Distributions across Training Set Permutations for

Secondary Education Application Branches (Reference Group in the

Categorical Predictor: Vocational Institute: Technical And Traffic): Adjusted

for Intercept Difference (Gender Difference Can Be Interpreted from the Sign,

But The Intercept Is Not Meaningful)

\begin{tabular}{lccccc}
\hline & $\mathrm{B}$ & $\mathrm{SE}$ & $2.5 \%$ & $97.5 \%$ & OR \\
\hline Intercept & 4.06 & 0.41 & 3.36 & 4.92 & 63.66 \\
Voc Cult & 0.15 & 0.25 & -0.37 & 0.63 & 1.19 \\
Voc Heal Care & -1.77 & 0.25 & -2.31 & -1.34 & 0.18 \\
Voc Beau Care & -3.60 & 1.02 & -6.33 & -2.52 & 0.04 \\
Voc Educ & -1.28 & 0.98 & -4.45 & 0.01 & 0.42 \\
Voc Natu Reso & -3.39 & 1.41 & -6.03 & -1.66 & 0.07 \\
Voc Secu & 0.91 & 0.50 & 0.04 & 1.87 & 3.30 \\
Voc Merc & 0.36 & 0.14 & 0.11 & 0.62 & 1.45 \\
Voc Data & 3.32 & 0.72 & 2.55 & 5.53 & 45.30 \\
Voc Trav Cate & -0.78 & 0.22 & -1.22 & -0.39 & 0.47 \\
High school Lang & -0.57 & 0.12 & -0.82 & -0.34 & 0.57 \\
High school Cult & -0.82 & 0.11 & -1.03 & -0.62 & 0.44 \\
High school Spor & 0.32 & 0.13 & 0.09 & 0.57 & 1.39 \\
High school Natu & 0.07 & 0.21 & -0.32 & 0.48 & 1.10 \\
High school Soci & 0.61 & 0.26 & 0.14 & 1.12 & 1.90 \\
High school Busi & 0.22 & 0.41 & -0.58 & 1.06 & 1.36 \\
High school Stei & -0.06 & 0.46 & -0.93 & 0.84 & 1.04 \\
High school Gene & -0.07 & 0.05 & -0.17 & 0.02 & 0.93 \\
\hline
\end{tabular}

Note: Abbreviations: Voc $=$ Vocational institute. Cult $=$ Cultural. Heal Care $=$ Health care. Beau Care $=$ Beauty care. Educ $=$ Educational. Natu Reso $=$ Natural resources and environment. Secu $=$ Security. Merc $=$ Business [merkonomi]. Data $=$ Information technology [datanomi]. Trav Cate $=$ Travel, catering, and domestic economics. Lang $=$ Language emphasis. Spor $=$ Sports and exercise emphasis. $\mathrm{Natu}=$ Natural science emphasis. Soci $=$ Social science emphasis. Busi $=$ Business emphasis. Stei $=$ Steiner high school. Norm $=$ General high schools. OR = Odds-ratio. Non-zero $=$ Number of permutations in which the coefficient was not penalized to zero. 
Table S13

Descriptive Statistics and Univariate Sex Differences for Observed Continuous Variables from the Entire Dataset

\begin{tabular}{|c|c|c|c|c|c|c|c|}
\hline & \multicolumn{3}{|c|}{ Girls } & \multicolumn{3}{|c|}{ Boys } & \multirow[t]{2}{*}{$d$} \\
\hline & $n$ & $M$ & $S D$ & $n$ & $M$ & $S D$ & \\
\hline \multicolumn{8}{|c|}{ Personality factors } \\
\hline $\mathrm{N}$ & 1386 & 3.23 & 1.04 & 1204 & 3.07 & 1.07 & -0.15 \\
\hline $\mathrm{E}$ & 1382 & 5.04 & 0.97 & 1207 & 4.73 & 1.04 & -0.31 \\
\hline $\mathrm{O}$ & 1382 & 4.90 & 0.91 & 1207 & 4.32 & 0.89 & -0.64 \\
\hline A & 1384 & 4.87 & 0.96 & 1206 & 4.48 & 0.88 & -0.42 \\
\hline $\mathrm{C}$ & 1379 & 4.93 & 1.00 & 1207 & 4.70 & 1.02 & -0.23 \\
\hline \multicolumn{8}{|c|}{ Personality facets } \\
\hline N1 & 1369 & 3.29 & 1.44 & 1196 & 2.86 & 1.55 & -0.29 \\
\hline E1 & 1363 & 5.24 & 1.51 & 1185 & 4.76 & 1.60 & -0.31 \\
\hline $\mathrm{O} 1$ & 1355 & 4.63 & 1.64 & 1164 & 4.33 & 1.65 & -0.18 \\
\hline A1 & 1368 & 4.31 & 1.53 & 1179 & 4.16 & 1.53 & -0.10 \\
\hline $\mathrm{C} 1$ & 1352 & 5.18 & 1.41 & 1173 & 4.98 & 1.55 & -0.14 \\
\hline N2 & 1354 & 3.20 & 1.41 & 1156 & 3.15 & 1.55 & -0.03 \\
\hline E2 & 1354 & 5.08 & 1.68 & 1178 & 4.78 & 1.74 & -0.18 \\
\hline $\mathrm{O} 2$ & 1360 & 0.36 & 1.85 & 1179 & -0.44 & 1.94 & -0.42 \\
\hline $\mathrm{A} 2$ & 1348 & 5.02 & 1.42 & 1162 & 4.62 & 1.40 & -0.28 \\
\hline $\mathrm{C} 2$ & 1352 & 4.74 & 1.66 & 1167 & 4.54 & 1.53 & -0.12 \\
\hline N3 & 1352 & 3.09 & 1.60 & 1169 & 2.91 & 1.55 & -0.11 \\
\hline E3 & 1349 & 4.56 & 1.47 & 1167 & 4.68 & 1.49 & 0.08 \\
\hline O3 & 1342 & 5.40 & 1.44 & 1156 & 4.50 & 1.54 & -0.61 \\
\hline A3 & 1346 & 5.37 & 1.40 & 1168 & 4.84 & 1.46 & -0.37 \\
\hline C3 & 1342 & 5.83 & 1.35 & 1159 & 5.22 & 1.46 & -0.44 \\
\hline N4 & 1343 & 2.97 & 1.46 & 1160 & 3.06 & 1.48 & 0.06 \\
\hline $\mathrm{E} 4$ & 1336 & 5.06 & 1.44 & 1157 & 4.79 & 1.50 & -0.18 \\
\hline O4 & 1339 & 4.31 & 1.57 & 1146 & 4.13 & 1.63 & -0.11 \\
\hline A4 & 1347 & 4.23 & 1.75 & 1153 & 4.01 & 1.71 & -0.13 \\
\hline $\mathrm{C} 4$ & 1347 & 4.60 & 1.47 & 1167 & 4.40 & 1.56 & -0.13 \\
\hline N5 & 1344 & 3.50 & 1.59 & 1169 & 3.29 & 1.64 & -0.13 \\
\hline E5 & 1342 & 5.09 & 1.42 & 1165 & 4.75 & 1.54 & -0.23 \\
\hline O5 & 1334 & 5.16 & 1.48 & 1160 & 4.83 & 1.63 & -0.21 \\
\hline A5 & 1339 & 4.76 & 1.28 & 1160 & 4.38 & 1.39 & -0.29 \\
\hline C5 & 1335 & 4.62 & 1.42 & 1155 & 4.64 & 1.49 & 0.01 \\
\hline N6 & 1339 & 3.29 & 1.46 & 1160 & 3.09 & 1.52 & -0.13 \\
\hline E6 & 1328 & 5.26 & 1.40 & 1158 & 4.65 & 1.54 & -0.42 \\
\hline O6 & 1326 & 5.41 & 1.46 & 1153 & 4.64 & 1.48 & -0.52 \\
\hline A6 & 1331 & 5.58 & 1.42 & 1158 & 4.91 & 1.46 & -0.47 \\
\hline C6 & 1329 & 4.65 & 1.55 & 1152 & 4.47 & 1.48 & -0.12 \\
\hline \multicolumn{8}{|c|}{ Values } \\
\hline PO & 1393 & 2.85 & 2.18 & 1244 & 3.87 & 2.30 & 0.46 \\
\hline $\mathrm{AC}$ & 1391 & 5.49 & 1.86 & 1242 & 5.68 & 1.91 & 0.10 \\
\hline
\end{tabular}




\begin{tabular}{|c|c|c|c|c|c|c|c|}
\hline $\mathrm{HE}$ & 1386 & 5.97 & 1.78 & 1236 & 5.77 & 1.92 & -0.11 \\
\hline ST & 1383 & 5.59 & 1.91 & 1228 & 5.33 & 1.96 & -0.13 \\
\hline $\mathrm{SD}$ & 1385 & 5.98 & 1.76 & 1241 & 5.54 & 1.92 & -0.24 \\
\hline UN & 1397 & 0.37 & 1.88 & 1233 & -0.43 & 2.06 & -0.41 \\
\hline $\mathrm{BE}$ & 1382 & 6.86 & 1.44 & 1233 & 5.93 & 1.85 & -0.56 \\
\hline TR & 1381 & 3.94 & 2.37 & 1235 & 4.23 & 2.30 & 0.12 \\
\hline $\mathrm{CO}$ & 1387 & 5.55 & 1.90 & 1235 & 5.47 & 1.90 & -0.04 \\
\hline $\mathrm{SE}$ & 1393 & 6.57 & 1.59 & 1241 & 6.23 & 1.76 & -0.20 \\
\hline \multicolumn{8}{|l|}{ Cognitive tests } \\
\hline $\begin{array}{l}\text { Invented } \\
\text { mathematical } \\
\text { concepts }\end{array}$ & 1724 & 0.06 & 2.31 & 1700 & -0.12 & 2.35 & -0.08 \\
\hline $\begin{array}{l}\text { Hidden arithmetic } \\
\text { operators }\end{array}$ & 1593 & 0.14 & 1.71 & 1542 & -0.20 & 1.81 & -0.19 \\
\hline $\begin{array}{l}\text { Visual working } \\
\text { memory }\end{array}$ & 1823 & -0.10 & 2.14 & 1798 & 0.01 & 2.25 & 0.05 \\
\hline Mental arithmetics & 1823 & -0.45 & 2.05 & 1798 & 0.32 & 1.99 & 0.38 \\
\hline $\begin{array}{l}\text { Analogical } \\
\text { reasoning }\end{array}$ & 1454 & 0.17 & 2.08 & 1452 & -0.21 & 1.96 & -0.19 \\
\hline $\begin{array}{l}\text { Reading } \\
\text { comprehension: } \\
\text { Multiple-choice }\end{array}$ & 1669 & 0.17 & 1.06 & 1593 & -0.20 & 1.15 & -0.33 \\
\hline $\begin{array}{l}\text { Verbal proportional } \\
\text { reasoning }\end{array}$ & 1784 & 0.12 & 1.75 & 1738 & -0.18 & 1.78 & -0.17 \\
\hline $\begin{array}{l}\text { Reading } \\
\text { comprehension: } \\
\text { Macroprocessing }\end{array}$ & 1416 & 0.31 & 3.18 & 1455 & -0.34 & 2.79 & -0.22 \\
\hline Scientific reasoning & 1713 & 0.00 & 1.44 & 1700 & -0.04 & 1.48 & -0.03 \\
\hline $\begin{array}{l}\mathrm{g} \\
\text { Academic grades }\end{array}$ & 1289 & 0.04 & 0.75 & 1339 & -0.08 & 0.76 & -0.16 \\
\hline Native language & 2050 & 0.30 & 0.99 & 2023 & -0.42 & 1.02 & -0.72 \\
\hline $\begin{array}{l}\text { First foreign } \\
\text { language }\end{array}$ & 2049 & 0.09 & 1.12 & 2019 & -0.16 & 1.14 & -0.22 \\
\hline Biology & 2051 & 0.22 & 1.11 & 2023 & -0.33 & 1.15 & -0.49 \\
\hline Physics & 2051 & 0.07 & 1.16 & 2023 & -0.19 & 1.21 & -0.22 \\
\hline Geography & 2051 & 0.16 & 1.12 & 2023 & -0.28 & 1.16 & -0.39 \\
\hline History & 2050 & 0.08 & 1.16 & 2022 & -0.17 & 1.16 & -0.22 \\
\hline Chemistry & 2051 & 0.16 & 1.17 & 2022 & -0.26 & 1.23 & -0.35 \\
\hline Home economics & 2036 & 0.31 & 0.77 & 2005 & -0.38 & 0.80 & -0.88 \\
\hline Handicraft & 2039 & 0.16 & 0.86 & 2003 & -0.21 & 0.86 & -0.43 \\
\hline Ethical studies & 2036 & 0.26 & 1.06 & 2012 & -0.35 & 1.14 & -0.55 \\
\hline Visual arts & 2044 & 0.35 & 0.73 & 2007 & -0.40 & 0.79 & -0.99 \\
\hline Physical training & 2050 & 0.02 & 0.91 & 2023 & -0.10 & 0.93 & -0.13 \\
\hline Mathematics & 2051 & 0.09 & 1.26 & 2022 & -0.20 & 1.30 & -0.23 \\
\hline Music & 2039 & 0.23 & 0.81 & 2003 & -0.29 & 0.92 & -0.60 \\
\hline Health education & 2049 & 0.32 & 0.96 & 2023 & -0.40 & 1.01 & -0.73 \\
\hline Social studies & 2050 & 0.17 & 1.13 & 2023 & -0.26 & 1.19 & -0.37 \\
\hline GPA & 2051 & 0.19 & 0.80 & 2023 & -0.28 & 0.82 & -0.58 \\
\hline
\end{tabular}


Note: See abbreviations from notes for Tables S2-S8. $d=$ univariate sex difference for observed scores. 
Table S14

Frequencies for Optionally Selected Subjects in the Entire

Dataset

\begin{tabular}{lcccc}
\hline & Girls \% & Boys \% & OR & $p$ \\
\hline Biology & 2.38 & 1.22 & 0.51 & .009 \\
History & 0.32 & 0.48 & 1.51 & .438 \\
Chemistry & 1.43 & 0.53 & 0.37 & .007 \\
Home economics & 70.57 & 68.84 & 0.92 & .249 \\
Handicraft & 37.90 & 44.64 & 1.32 & $<.001$ \\
Ethical studies & 40.13 & 20.06 & 0.37 & $<.001$ \\
Physical training & 28.59 & 56.26 & 3.21 & $<.001$ \\
Mathematics & 2.38 & 2.97 & 1.26 & .262 \\
Music & 25.15 & 16.30 & 0.58 & $<.001$ \\
Social studies & 0.32 & 0.48 & 1.51 & .438 \\
\hline
\end{tabular}

Note: $\mathrm{OR}=$ Univariate Odds-ratio (values $>1$ indicate that boys are more likely to select given subject). Non-zero $=$ Number of permutations in which the coefficient was not penalized to zero. 
Table S15

Frequencies for Field of Education Preferences in the Secondary School Applications

\begin{tabular}{lcccc}
\hline & Girls \% & Boys \% & OR & $p$ \\
\hline Voc Cult & 1.61 & 1.84 & 1.15 & .572 \\
Voc Heal Care & 5.62 & 0.95 & 0.16 & $<.001$ \\
Voc Beau Care & 3.22 & 0.10 & 0.03 & $<.001$ \\
Voc Educ & 0.63 & 0.20 & 0.31 & .042 \\
Voc Natu Reso & 0.93 & 0.05 & 0.05 & .004 \\
Voc Secu & 0.44 & 1.05 & 2.39 & .029 \\
Voc Merc & 4.35 & 6.27 & 1.47 & .006 \\
Voc Data & 0.20 & 5.33 & 28.76 & $<.001$ \\
Voc Tech Traf & 1.42 & 15.09 & 12.37 & $<.001$ \\
Voc Trav Cate & 3.37 & 1.54 & 0.45 & $<.001$ \\
High school Lang & 9.96 & 5.68 & 0.54 & $<.001$ \\
High school Cult & 12.89 & 5.73 & 0.41 & $<.001$ \\
High school Spor & 5.57 & 7.77 & 1.43 & .005 \\
High school Natu & 2.25 & 2.39 & 1.07 & .760 \\
High school Soci & 1.22 & 2.24 & 1.86 & .014 \\
High school Busi & 0.68 & 0.85 & 1.24 & .552 \\
High school Stei & 0.63 & 0.60 & 0.94 & .880 \\
High school Gene & 45.02 & 42.33 & 0.90 & .084 \\
\hline
\end{tabular}

Note: Abbreviations: Voc $=$ Vocational institute. $\mathrm{Cult}=$ Cultural. Heal Care $=$ Health care. Beau Care $=$ Beauty care. Educ $=$ Educational. Natu Reso $=$ Natural resources and environment. Secu $=$ Security. Merc $=$ Business [merkonomi]. Data $=$ Information technology [datanomi]. Trav Cate $=$ Travel, catering, and domestic economics. Tech Traf $=$ Technology and Traffic. Lang $=$ Language emphasis. Spor $=$ Sports and exercise emphasis. Natu $=$ Natural science emphasis. Soci $=$ Social science emphasis. Busi $=$ Business emphasis. Stei $=$ Steiner high school. Norm $=$ General high schools. OR $=$ Univariate Odds-ratio (values $>1$ indicate that boys are more likely to select given subject). 
Same data for training and testing

\begin{tabular}{lcccccc} 
& $\begin{array}{c}\text { Mahalanobis' } \\
D\end{array}$ & $\begin{array}{c}\text { Mahalanobis' } \\
D_{\mathrm{u}}\end{array}$ & $\begin{array}{c}\text { Mahalanobis' } \\
D_{\text {corrected }}\end{array}$ & $\begin{array}{c}\text { Elastic } \\
\text { net } D\end{array}$ & $\begin{array}{c}\text { Kernel } \\
\text { OVL }\end{array}$ & $\begin{array}{c}\text { Mean Elastic } \\
\text { net D } \\
\text { (Table 1) }\end{array}$ \\
\hline Personality factors & 0.89 & 0.88 & 1.11 & 0.89 & 68.27 & 0.86 \\
Personality facets & 1.07 & 1.06 & & 1.13 & 61.54 & 0.95 \\
Personal values & 0.80 & 0.79 & & 0.76 & 72.55 & 0.75 \\
Cognitive tests & 0.65 & 0.65 & 0.76 & 0.68 & 74.66 & 0.60 \\
Grades & 1.51 & 1.50 & & 1.51 & 53.58 & 1.48 \\
Optional subjects & 0.74 & 0.73 & & 0.74 & 73.16 & 0.72 \\
Applied education & 0.80 & 0.79 & & 0.81 & 70.54 & 0.77 \\
\hline
\end{tabular}

Note. Mahalanobis' $D_{\text {corrected }}$ calculated only for domains for which input variables were scales for which reliability could be calculated. For reliability, $\omega_{t}$ was used for personality factors, and $\pi_{(2)}$ for cognitive tests. Mean Elastic net D estimates, provided here for comparison, are identical to those presented in Table 1 in the article. Kernel OVL is non-parametric variant for estimation of distribution overlap between boys and girls, calculated here from the entire data as opposed to the estimates in Table 1 that were calculated based on Mean Elastic Net D. 
Table S17

Zero-order Correlations between FM Scores

\begin{tabular}{llll}
\hline & & $r$ & CI \\
\hline Personality & Values & .44 & {$[.39, .48]$} \\
Personality & Cognitive tests & .17 & {$[.13, .21]$} \\
Personality & Grades & .34 & {$[.30, .38]$} \\
Personality & Optional subjects & .20 & {$[.15, .24]$} \\
Personality & Application & .18 & {$[.13, .22]$} \\
Values & Cognitive tests & .19 & {$[.15, .24]$} \\
Values & Grades & .29 & {$[.25, .32]$} \\
Values & Optional subjects & .16 & {$[.12, .20]$} \\
Values & Application & .15 & {$[.11, .19]$} \\
Cognitive tests & Grades & .25 & {$[.21, .29]$} \\
Cognitive tests & Optional subjects & .16 & {$[.13, .20]$} \\
Cognitive tests & Application & .13 & {$[.10, .17]$} \\
Grades & Optional subjects & .27 & {$[.23, .30]$} \\
Grades & Application & .28 & {$[.24, .32]$} \\
Optional subjects & Application & .17 & {$[.14, .21]$} \\
\hline
\end{tabular}

Note: $\mathrm{CI}=$ confidence interval based on percentile values, $2.5 \%$ and $97.5 \%$, across the permutations. 
Table S18

Confirmatory Factor Analysis Based on Covariance Matrix Constructed from Mean Partial Correlations and Pooled Standard Deviations across Sexes

\begin{tabular}{|c|c|c|c|c|c|c|}
\hline \multirow[b]{2}{*}{ FM-Score } & \multicolumn{3}{|c|}{ Unstandardized solution } & \multicolumn{3}{|c|}{ Standardized solution } \\
\hline & Loading & $S E$ & $p$ & Loading & $S E$ & $p$ \\
\hline Personality & 1 & & & .571 & 0.060 & $<.001$ \\
\hline Values & 0.783 & 0.156 & $<.001$ & .578 & 0.061 & $<.001$ \\
\hline $\begin{array}{l}\text { Cognitive } \\
\text { tests }\end{array}$ & 0.179 & 0.049 & $<.001$ & .163 & 0.041 & $<.001$ \\
\hline Grades & 0.577 & 0.127 & $<.001$ & .216 & 0.040 & $<.001$ \\
\hline $\begin{array}{l}\text { Optional } \\
\text { subjects }\end{array}$ & 0.153 & 0.054 & .005 & .123 & 0.041 & .003 \\
\hline Application & 0.151 & 0.079 & .057 & .080 & 0.041 & .051 \\
\hline
\end{tabular}

Note: Model fit: $\chi^{2}(9)=26.78, p=.002 . C F I=.911, T L I=.851, R M S E A=$ $.042[.024, .060], S R M R=.032$. Sample size $=1144$ (smallest pairwise correlation sample size in testing data splits). 
A.

r: zero-order $=0.5$, partial $=0$

girls $=0$, boys $=0$

$D$ : domain $A=2$, domain $B=2$
B.

r: zero-order $=0.1$, partial $=0$

girls $=0$, boys $=0$

$\mathrm{D}$ : domain $\mathrm{A}=0.5$, domain $\mathrm{B}=0.5$

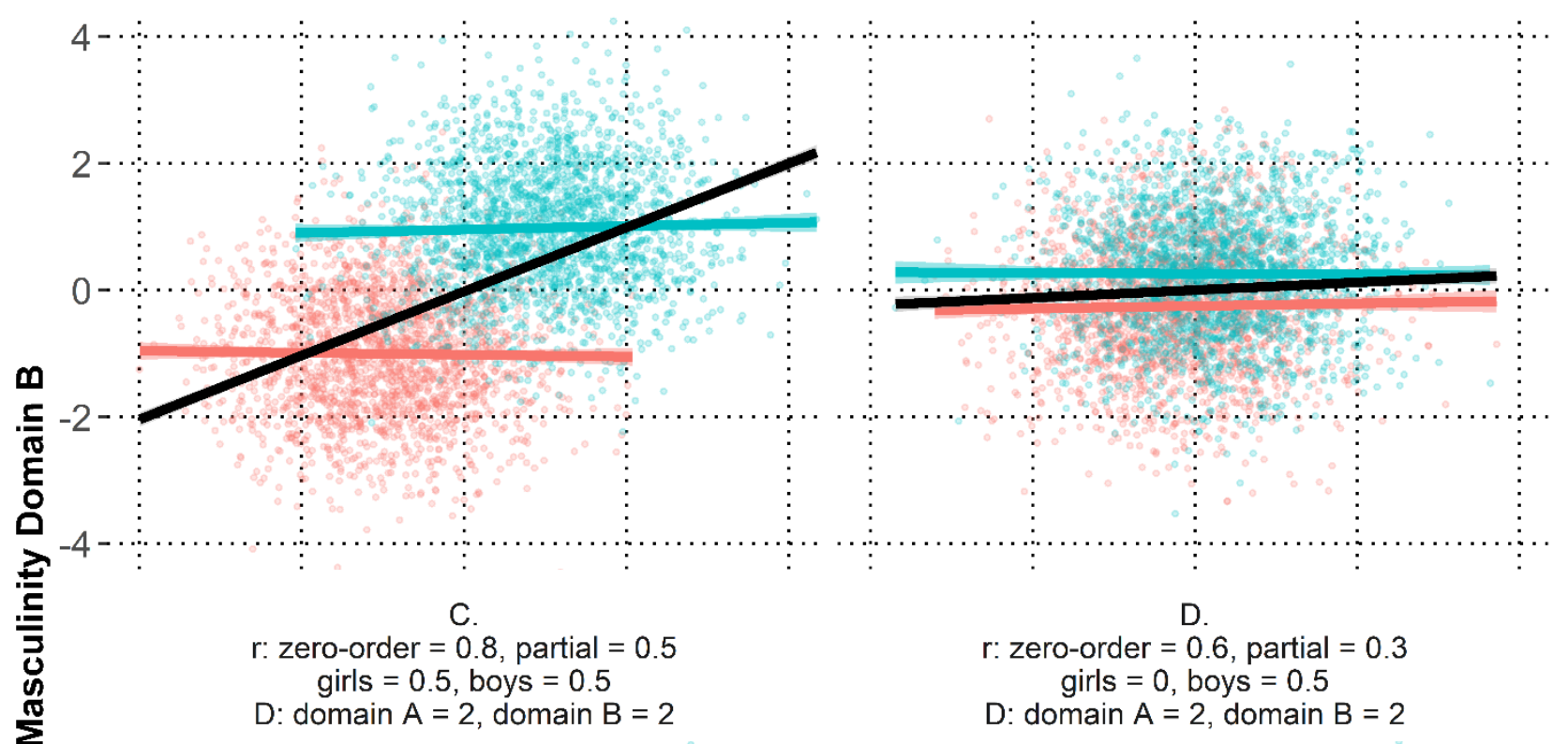

Femininity-Masculinity Domain A

Figure S1. Simulated illustration of sex difference confounded associations between femininitymasculinity scores (genderedness). Black slopes indicate zero-order associations, whereas blue and red lines indicate within-sex association for boys and girls, respectively. Panel A illustrates $r=.50$ association that is completely confounded by large sex differences in domains A and B (within-sex and partial associations are zero). Panel B illustrates similar scenario but with smaller sex differences $(D \mathrm{~s}=0.50)$. Panel $\mathrm{C}$ illustrates inflation of genderedness association $r=.50$ to $r=.80$ by sex differences. Panel D illustrates how zero-order and partial could both be misleading for the other sex (here girls show no association between domains, but zero-order and partial are both indicative of an association). 